\title{
On the Competing Roles of Fault Reactivation and Brittle Failure in Generating Plate Tectonics from Mantle Convection
}

\author{
Michael Gurnis \\ Seismological Laboratory, California Institute of Technology, Pasadena, California
}

Shijie Zhong

Department of Earth, Atmospheric, and Planetary Sciences, Massachusetts Institute of Technology, Cambridge, Massachusetts

John $\operatorname{Toth}^{1}$

Seismological Laboratory, California Institute of Technology, Pasadena, California

Fault reactivation plays a fundamental role in the generation of plate tec-
tonics from mantle convection. Converging and transform plate margins are
mechanically weak due to both preexisting faults and preserved shear zones
within the crust and lithosphere, on the one hand, and continuous brittle
failure of lithosphere, on the other hand. Transform margins are the site
for nucleating new converging margins. Lithospheric earthquakes demon-
strate that oceanic lithosphere within a trench can deform as fast as the
upper mantle. Models demonstrate that faulted converging plate margins
contribute to producing plate tectonic-like motion. Preexisting faults and
a power law plastic rheology dynamically interact and together give rise to
plate-like motion. Faults have an important influence over outer rise and
trench topography and by comparing models with observations, interplate
stress is about $10-30 \mathrm{MPa}$. Subduction can initiate on preexisting faults
when interplate coupling is as high as $10-30$ MPa if the oceanic plate al-
ready has slabs attached to it - as was the case for the Pacific plate when
the Marianas nucleated. Modeled plates only change velocity slowly in re-
sponse to the initiation of new subduction zones; the initiation of subduction
in the Western Pacific at $\approx 45$ Ma was likely the result of a change in Pa-
cific plate motion as opposed to causing the change in the direction of plate
motion. The locations of the greatest amount of present day brittle failure

The History and Dynamics of Global Plate Motions

Geophysical Monograph 121

Copyright 2000 by the American Geophysical Union

\footnotetext{
${ }^{1}$ Now at Shell International Exploration and Production, Rijswijk, Netherlands
} 
within oceanic lithosphere are not located at arbitrary positions on oceanic plates, rather brittle failure occurs in close proximity to long lived zones of preexisting weakness. Old weak structures are reused by the convecting system because it takes less energy to reactivate a preexisting structure than it does to create an entirely new plate margin from pristine, intact lithosphere.

\section{INTRODUCTION}

Plate tectonics is a kinematic description in which the outer shell of the Earth is divided into a number of plates or rigid spherical caps which move with respect to each other. Oceanic plates represent the top thermal boundary layer of mantle convection [Davies and Richards, 1992] and this boundary layer sinks (subducts) into the mantle at converging margins. The motion of plates (their speed and direction) is a balance between the buoyancy of cooling and thickening oceanic lithosphere and subducted slabs, on the one hand, and viscous flow, on the other [Hager and O'Connell, 1981]. Plate motion and the associated mantle flow appears to be a simple mode of thermal convection and has been described as a fluid dynamical process [Turcotte and Oxburgh, 1967]. The process, however, is not solely fluid dynamic because (a) oceanic plates are mostly rigid with little deformation within their interior and (b) an appreciable amount of plate motion occurs by strikeslip. A substantial fraction of the total dissipation associated with plate motion could occur in the bending of the oceanic lithosphere as it subducts [Conrad and Hager, 1999]. Why the Earth has plate tectonics is a significant unanswered question which is addressed in this paper as well as others in this volume by Bercovici et al. [1999] and Tackley [1999].

Qualitatively, one solution to the existence of plate tectonics lies in a balance between thermal convection, the thermally activated rheology of silicates at high temperatures, and brittle failure of rocks at low PT. Plate driving forces are largest at converging margins above subducting slabs so that otherwise cold and strong lithosphere fails and gives rise to weak plate margins. With this model, the lithosphere rapidly fails on geological time-scales under the action of tectonic stress. A number of studies concerning the dynamics of plate tectonics generation assume that the lithosphere fails with the application of tectonic stress [Bercovici 1993; 1995; Moresi and Solomatov, 1998; Tackley, 1998]. Since the rheologies used in these models do not consider the deformational history of the material, we refer to this as the instantaneous rheology model. We will argue that this is one fundamental component generating plate tectonics. In addition, the mechanical memory of the crust and lithosphere could also play a fundamental, but not an exclusive, role in the generation of plate tectonics. An important piece of evidence pointing toward this alternative hypothesis is that long lived zones of preexisting weakness and preexisting faults control the location of plate margins. We will argue that old weak structures are reused by the convecting system because it takes less energy to reactivate a preexisting structure than it does to create an entirely new plate margin from pristine, intact lithosphere. We will argue that it is essential that preexisting structures be incorporated into both instantaneous models of mantle flow and time-dependent, fully dynamic models simulating plate motions on time-scales less than $\sim 10^{8}-10^{9}$ yrs.

A long term goal of geophysics is the formulation of dynamically self consistent, time-dependent models of mantle convection in which plate tectonics naturally arises. This is an important long term objective because it not only relates to why the Earth has plate tectonics while other planets, particularly Venus, do not, but because the resolution of this problem will lead to the development of dynamic models integrating a wide variety of geological, geophysical, and geochemical observations [e.g., Gurnis et al., 1998]. In this paper, we integrate results from seismology, plate tectonic reconstructions, other geophysical observations, and dynamic simulations to show that the reactivation of preexisting fault zones must play a fundamental role in controlling large-scale mantle dynamics and that use of instantaneous rheologies without consideration of deformational history is not a satisfactory solution to geodynamic problems.

\section{DEFORMATION FIELD OF A CONVERGING MARGIN}

An essential component of our hypothesis is that both preexisting structures and continuous failure of the oceanic lithosphere play fundamental roles in mantle dynamics. In order to demonstrate the significance of the continuous failure or weakening of the oceanic lithosphere we focus on the deformation field at subducting margins. Moreover, the observed character of subducting margins guides the formulation of faults in geodynamic models as described in Section 5.1. Although complex, the spatial and temporal patterns of 
deformation are essential constraints on how subduction operates on mantle convection time-scales.

There are two forms of seismic deformation within subduction zones: interplate and intraplate deformation. Interplate deformation (Fig. 1) is exemplified by great earthquakes, large thrust events (with moment magnitudes, $M_{w}, 8.2$ or greater) occurring on the interface between subducting and overriding plates; the May, 1960 Chilean earthquake is an example. Subduction zones have been classified into those which have great earthquakes (called coupled because of a substantial amount of mechanical coupling) and those which have no great earthquakes (uncoupled) [Uyeda and Kanamori, 1979]. Within coupled subduction zones, the overriding plate is generally in a compressive state and the slabs have moderate to shallow dip angles. The subduction zones in South America, Alaska, the Aleutians, and Kamchatka are coupled [Kanamori, 1986]. Coupled subduction zones occur within intermediate age lithosphere $(\approx 20-80 \mathrm{Ma})$ where the ratio between interplate seismic slip to the slip inferred from plate motions is unity [Kamamori and Astiz, 1985]. Uncoupled subduction zones are associated with back-arc opening, steeply dipping slabs and old oceanic lithosphere; the Marianas is an example. Some subduction zones are intermediate in their seismic coupling; subduction at the Tonga and N. Japan trenches are examples.

Not all seismic deformation within converging margins occurs by thrusting between subducting and overriding plates. As the subducting oceanic plate moves toward the site of interplate deformation, seismic activity increases with the occurrence of outer rise earthquakes. The outer rise is a topographic undulation $(\approx 200$ meters in height) located a few hundred kilometers ocean ward of trenches - easily visible on the map of free-air gravity of the western Pacific (Plate 1). Outer rise earthquakes are usually tensional [Christensen and Ruff, 1988] and have been attributed to the bending of a strong elastic plate. When a rigid beam is bent, it will be in tension through its upper half and in compression through its lower [Chapple and Forsyth, 1979]. Outer rise tensional events have been interpreted as the brittle failure of the upper region of the elastic lithosphere. A bending plate which undergoes plastic failure must still be capable of supporting elastic stresses greater than $\approx 500 \mathrm{MPa}$ within its core if trench-forebulge bathymetry is to be matched [McAdoo et al., 1978; Chapple and Forsyth, 1979]. The normal conceptualization of the deformation field associated with subduction is that the oceanic lithosphere is strong as indicated by the presence of the outer rise
(Plate 1). However, there are three reasons to question this hypothesis: the occurrence of earthquakes which completely fracture oceanic lithosphere, the space-time occurrence of outer rise earthquakes demonstrating that the outer rise is a dynamic feature, and the ability to generate trench-forebulge bathymetry dynamically with lithosphere which has no long-term elastic strength.

So called lithospheric earthquakes within the subducting oceanic plate have been identified [Kikuchi and Kanamori, 1995] and occur below and ocean ward of the seismic coupling zone (Fig. 1). Lithospheric earthquakes (large-magnitude events on faults which cut completely through the $100 \mathrm{~km}$ thick lithosphere) show that the oceanic lithosphere undergoes rapid, permanent deformation within the trench environment, contrary to the conventional model of a bending plate. One such event is the 1933 Sanriku $\left(M_{w}=8.4\right)$ tensional event which occurred within the oceanic lithosphere ocean ward of the (intermediately coupled) Japan trench (Plate 1) [Kanamori, 1971]. The event ruptured down to $\approx 100 \mathrm{~km}$, completely fracturing the oceanic lithosphere in a location where the outer rise is well developed (Plate 1). Although only 12 events between magnitude, $M_{w}, 7.2$ and 8.3, have been identified globally the rate of seismic moment release is substantial. The approximate location with respect to the trench, extent of rupture, and slip are illustrated schematically in Figure 1. Using the tabulation of seismic moments in Kikuchi and Kanamori [1995], we can estimate the volumetric seismic strain rate within the oceanic lithosphere as it slides by the surface of interplate deformation. The following estimate, which excludes the great thrust earthquakes, must be a lower limit on total strain since other deformation mechanisms could be in operation besides seismic slip (aseismic slip on faults, plastic deformation, etc.). It can be shown that

$$
\dot{\epsilon} \approx \frac{\Sigma M_{o}}{2 \mu V \Delta T}
$$

where $\dot{\epsilon}$ is the average strain rate within the lithosphere, $\Sigma M_{o}$ is the cumulative seismic moment release which occurs in a volume, $V$, over a time, $\Delta T$, and $\mu$ is the shear modulus [Bevis, 1988]. The events occurred within a volume, $V=d L W$, where $d$ is the depth range of rupture associated with lithospheric earthquakes, $L$ is the length of trenches, and $W$ is the horizontal length scale over which the earthquakes occur. The lithospheric earthquakes occurred over a $65 \mathrm{yr}$ period and if we assume that $d=100 \mathrm{~km}, L=4 \times 10^{4} \mathrm{~km}$, and $W=200$ $\mathrm{km}$, then $\dot{\epsilon} \approx 1 \times 10^{-16} \mathrm{~s}^{-1}$. However, as shown in Plate 1 , four of these events occur in a $800 \mathrm{~km}$ segment along 


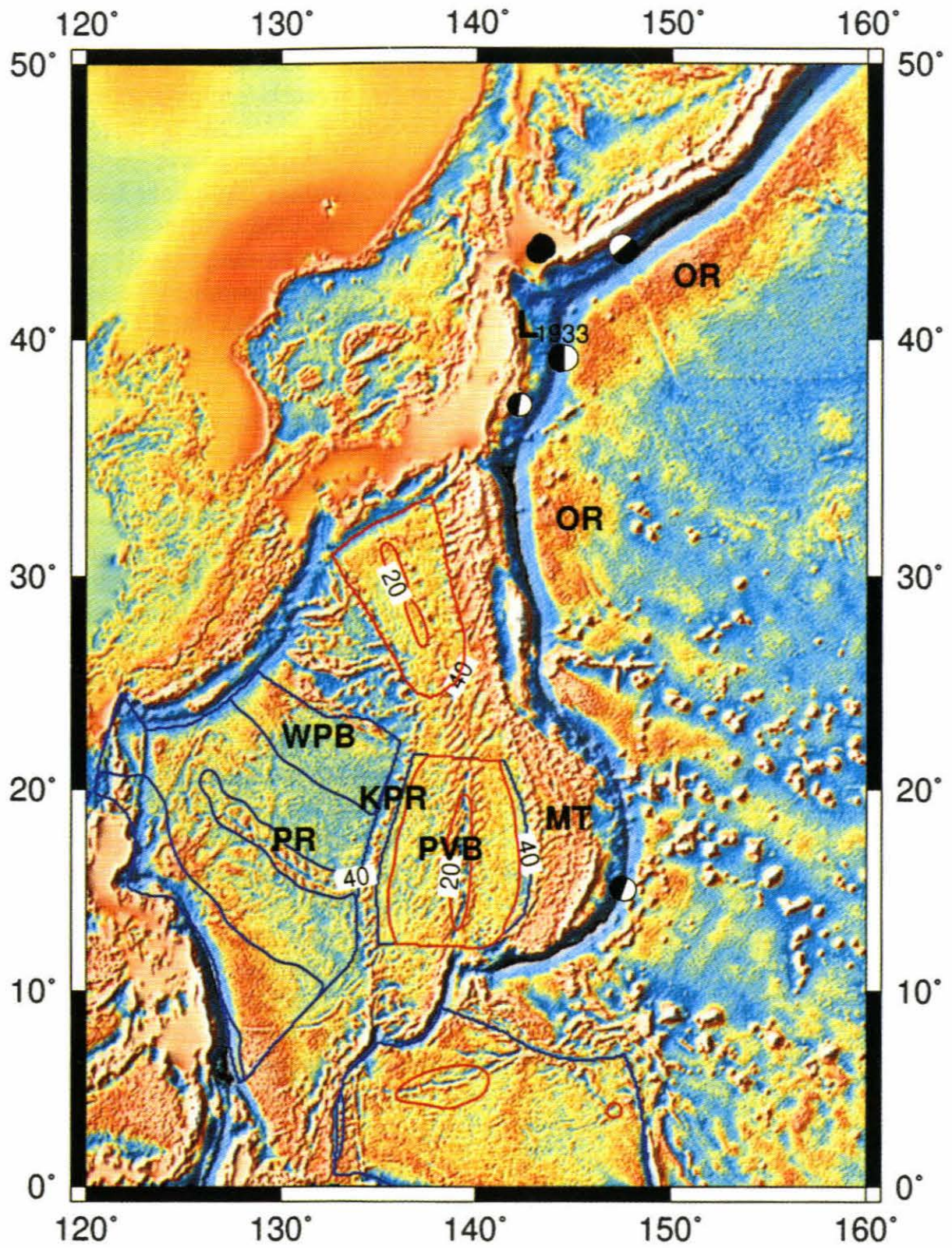

Plate 1. Free-air gravity (from Sandwell and Smith [1997]) of the Western Pacific showing features described in the text. The focal mechanisms of lithospheric earthquakes are shown in black (from references cited in Kikuchi and Kanamori [1995]. In the area around the Japan trench these earthquakes are labeled with an L. The 1933 Sanriku event is labeled. Contours of ages (from Müller et al. [1997]) for marginal basins are shown in red for 10-30 Ma crust and in blue for 40-60 Ma crust. The following features are labeled: the West Philippine Basin (WPB), Philippine Ridge (PR), Kyushu-Palau Ridge (KPR), Parece Vela Basin (PVB), the Mariana Trough (MT), and the outer rise (OR). 


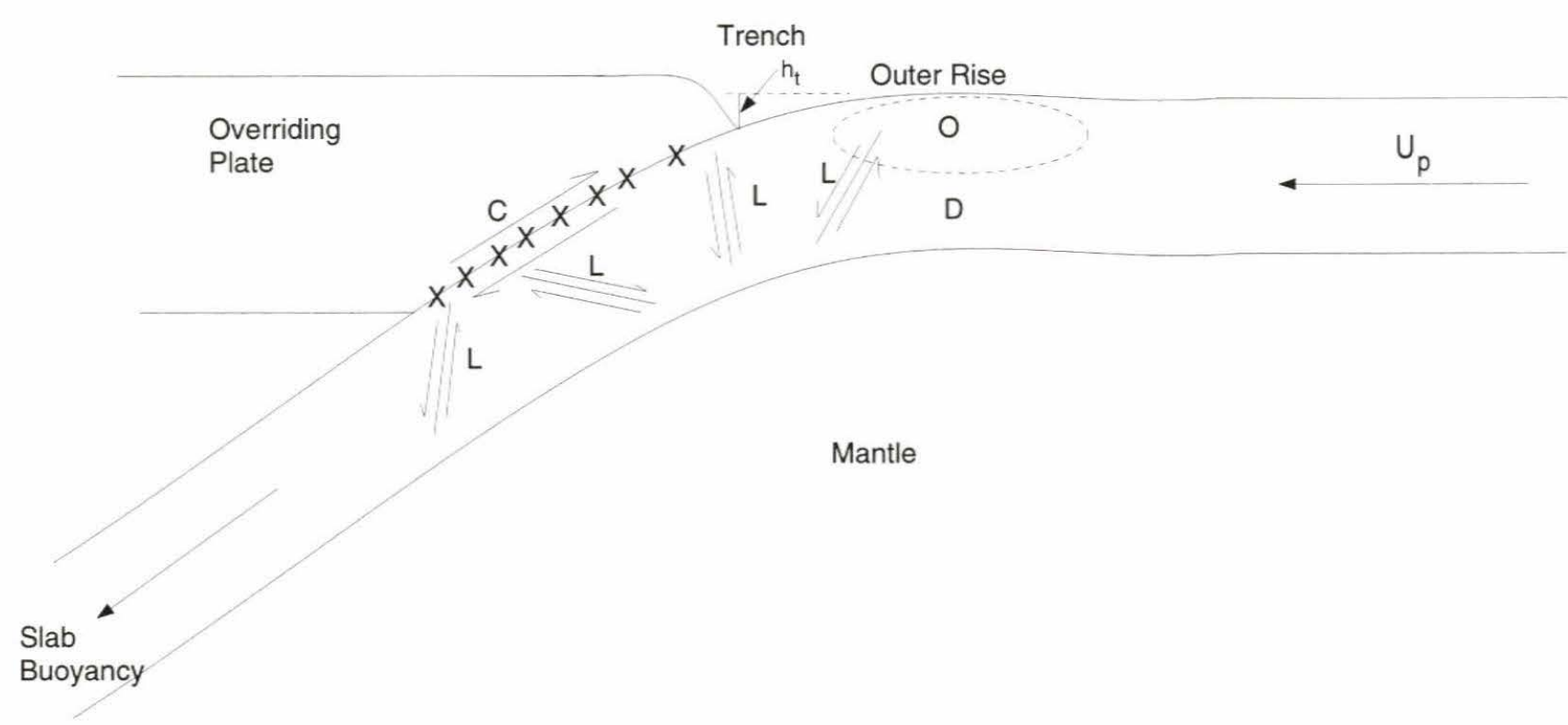

Figure 1. Schematic cross-section through a generic converging margins showing features described in the text. The interplate coupling zone is labeled with $\mathrm{C}$, lithospheric earthquakes with $\mathrm{L}$, location of the outer rise, $\mathrm{O}$, area of the lower lithosphere below the outer rise, $\mathrm{D}$, trench depth with $h_{t}$, and plate velocity with $U_{p}$.

the strike of the Japan trench where the strain rate is found to be $\dot{\epsilon} \approx 2 \times 10^{-15} \mathrm{~s}^{-1}$. These strain rates can be compared to those which occur in the low viscosity upper mantle which is on the order of $\approx 5 \mathrm{~cm} / \mathrm{yr} \div 10^{3}$ $\mathrm{km}=2 \times 10^{-15} \mathrm{~s}^{-1}$. The worldwide average strain rate within the oceanic lithosphere as it traverses the trench environment is nearly as high as strain rates within the upper mantle and the lithosphere in certain locations, like the Japan trench, can deform as fast as the upper mantle.

Although it is unlikely that oceanic lithosphere can be perfectly described as a viscous material as it slides by the plane of interplate coupling, it does appear to be pervasively fractured. We can make an order of magnitude estimate on the bulk effective viscosity of the lithosphere within the trench by assuming that effective viscosity, $\eta_{\text {eff }} \sim \tau / \dot{\epsilon}$ where $\tau$ is the deviatoric stress. As we show below, the deviatoric stress within the lithosphere near the trench is approximately proportional to trench depth (e.g. $\tau \sim \rho g h_{t}$, where $h_{t}$ is trench depth, Fig. 1). $h_{t}$, globally, is on average about $4 \mathrm{~km}$ and about $2 \mathrm{~km}$ within the Japan trench [Jarrard, 1986]. Consequently, we estimate a $\eta_{\text {eff }} \sim 10^{23}-10^{24} \mathrm{~Pa} \mathrm{~s}$ (globally averaged) and $\sim 10^{22} \mathrm{~Pa} \mathrm{~s}$ (Japan trench).

The occurrence of outer rise earthquakes in space and time show that the outer rise is a dynamic feature where stresses evolve over $\sim 10-100 \mathrm{~km}$ scales in response to interplate interactions [Christensen and Ruff, 1988]. Outer rise events are primarily tensional. The less common compressional events occur in known seismic gaps or precede large interplate events [Christensen and Ruff, 1988]. Tensional events are consistent with the continuous pulling of the oceanic plate by slab pull, not the bending of an elastic plate. Great earthquakes are always followed by tensional outer rise earthquakes. Within uncoupled plate margins only tensional events occur. The 1952 Kamchatka $\left(M_{w}=9.0\right)$ interplate event on a coupled plate margin was followed by a series of tensional outer rise events which lasted until 1981-82 when the mechanism switched to compressional [Christensen and Ruff, 1988]. If we assume that this $30 \mathrm{yr}$ period represents the Maxwell time $\left(\tau_{M}=\eta / \mu\right)$ of the lithosphere within the trench, then the effective viscosity of the lithosphere within the trench is $\sim 10^{20} \mathrm{~Pa}$-s. However, this value is as small as typical upper mantle viscosities such that some of the post-seismic relaxation could be occurring within the upper mantle instead of within the lithosphere. Clearly, an explicit model of the process will be required to understand how robust this value is, but even if the Maxwell time is two orders of magnitude larger, the viscosity we obtain is still quite small. 
Finally, there is no need for the oceanic lithosphere to have any elastic strength within the trench. The elastic flexure models have long been criticized because they require the lithosphere to support kilobars of stress in excess of what can be supported by lithospheric materials [Kohlstedt et al., 1995]. However, if the topography is generated by viscous flow then such high stresses are not required [DeBremaecker, 1977; Melosh, 1978]. We show below that trench-forebulge topography can be dynamically maintained in models in which the lithosphere not only lacks elastic strength but has low effective viscosity within the trench environment.

Before the oceanic lithosphere enters the trench environment, it has considerable strength as indicated by distinct flexural bulges around oceanic islands. But by the time the lithosphere has passed through the trench environment, it has undergone considerable deformation. Clearly, subducting oceanic lithosphere is weak in comparison to the bulk of the lithosphere. This demonstrates that a substantial component of mantle rheology responds instantaneously on geological time-scales and this point is emphasized because this brittle failure contrasts with historical weakness described in Section 4.

\section{THE STRENGTH OF FAULTS}

If faults are substantially weaker than any other part of the plate tectonic system, they will always be used to accommodate deformation in lieu of creating new plate margins. It has long been appreciated that the large fault zones which accommodate the strain associated with plate tectonics are not only much weaker than intraplate regions but substantially weaker than predicted by extrapolation of experimental rock mechanics data.

The stress drop in large interplate earthquakes, on average $3 \mathrm{MPa}$ [Kanamori, 1980], shows that faults are weak. Although stress drops may only reflect that released during earthquakes and not the absolute value of stress across large fault zones [Kanamori, 1994], estimates of absolute stress across the San Andreas transform fault in California must be $10 \mathrm{MPa}$ or less because of the lack of a frictionally developed heat flow anomaly in the vicinity of the fault [Lachenbruch and Sass, 1988]. The weakness of large faults between plates is corroborated by the direction of maximum principle stress of small adjacent events in both strike slip [Kanamori, 1980] and convergent settings [Magee and Zoback, 1993]. The weakness of the San Andreas fault is corroborated by the complete absence of right lateral shear as inferred from stress measurement in deep boreholes [Zoback and Healy, 1992]. As we describe below, such estimates are consistent with $10-30 \mathrm{MPa}$ absolute shear stresses on faults inferred from a comparison of dynamic models of trenches driven by the buoyancy of slabs and trench depths at ocean-ocean converging margins [Zhong and Gurnis, 1992; 1994].

Outside of major tectonic faults, however, lithosphere appears much stronger and capable of supporting much larger stress. The large topography in some regions especially near seamounts induce large local stresses ( $200 \mathrm{MPa})$ [Artyushkov, 1973; Jeffreys, 1970]; since there is little observed deformation in these regions, including seismicity, the large stress implies these regions must be strong. That the lithosphere resists deformation (and remains strong) even when subject to large forces is fundamental. The properties of the lithosphere subject to deformation in trench environments and of lithosphere at seamounts must be fundamentally different. We suggest that deformation of oceanic lithosphere at trenches should not be modeled by flexure of an elastic plate.

Large faults are probably weak because the rocks making up fault zones at depth have much finer grain size than the host country rock [Watterson, 1975; White, 1976]. White [1976] suggested that fine grain size allowed a change in deformation from dislocation creep to one in which grain boundary sliding dominated. The exact mechanism is a subject of debate and continuing research, but reduction of grain size, especially in the presence of water, continues to be the preferred mechanism for the weakness of fault zones at depth [Vissers et al., 1995; Jaroslow et al., 1996; Imber et al., 1997] .

\section{FAULT LONGEVITY AND REACTIVATION}

The plate tectonic record since the Mesozoic demonstrates that as oceanic plates evolve, either reuse of existing fault zones or reactivation of dormant structures is the preferred mode of deformation rather than the generation of entirely new weak margins from homogeneous and strong lithosphere. This is just a specific example of a widely recognized principle in geology that not only do major fault zones change their tectonic sense during the course of time [White and Green, 1986], but fault zones can remain in existence for greater than $10^{9}$ yrs (for example, Sykes [1978]). When continents breakup, new diverging plate margins (rifts) do not randomly occur within continental plates, rather they tend to follow preexisting structures, old orogenic belts in particular. The present rift system in East Africa, active since the Tertiary, has followed the margins of cratons which have been reactivated many times in the last 3 Gyr [McConnell, 1972]. When N. America split from 
Africa during the Mesozoic, the rifting followed the $\mathrm{Pa}$ leozoic suture zone between the two continents [Wilson, 1966]. Although this evolution from old suture zone to new rift is important, we focus our discussion on how fault zones evolve or have been reactivated from transform to convergence, from convergence to transform, and from divergence to strike-slip (Fig. 2).

The reuse of an active transform to create a new subduction zone can be demonstrated from the history of basins behind the Marianas trench. At the Marianas trench, the Pacific plate has been subducting under the Philippine plate for about $40 \mathrm{Myr}$. However, within the West Philippine Basin (Plate 1) there are WNW trending magnetic anomalies, the youngest being 40 $\mathrm{Ma}$, and these are perpendicular to the present NS trending converging margin [Ben-Avraham and Uyeda, 1983]. The east-west magnetic lineations are symmetrical with respect to the Philippine Ridge an extinct ridge which ceased spreading at about $40 \mathrm{Ma}$. These magnetic anomalies abruptly terminate at the KyushuPalau Ridge which can be clearly seen in Plate 1 . The Kyushu-Palau Ridge forms the western boundary of the Parece Vela Basin which opened between about 40 and $10 \mathrm{Ma}$. The Parece Vela Basin was the first of two back-arc basins formed by the rollback of the Mariana trench. There was extensive Eocene volcanism along the Kyushu-Palau Ridge when subduction was presumably initiated [Stern and Bloomer, 1992]. The arrangement of the tectonic elements, tectonic fabric, sea-floor ages, and magmatic history are all consistent with the hypothesis that a new converging margin (the Mariana trench) formed on a fracture zone (the KyushuPalau Ridge) and then trapped the oceanic crust behind the active trench [Uyeda and Ben-Avraham, 1972; BenAvraham and Uyeda, 1983; Stern and Bloomer, 1992].

The conversion of old fracture zones and transform faults into converging margins may be a general process which occurs repeatedly during the evolution of an ocean basin. The evolution of the Aleutian trench is similar to the Marianas: within the Bering sea there are N-S trending early Cretaceous magnetic lineations [Cooper et al., 1976] which are perpendicular to the Aleutian trench, such that the trench probably formed on an E-W trending fracture zone of the Kula plate at $55 \mathrm{Ma}$ [Scholl et al., 1986]. Another example of an incipient subduction zone along a transform plate boundary is the Puysegur ridge and trench at the northern end of the Macquarie ridge complex [Collot et al., 1995]. Oblique convergence occurs along the Puysegur ridge where subduction is propagating southwards along the strike slip boundary. Earthquake focal mechanisms show a trench-parallel sub-vertical strike-slip fault beneath the ridge axial valley, and a southeastward, shallow dipping oblique thrust [Collot et al., 1995]. The development of the subduction zone is being facilitated by the development of reverse faults, which accommodate the normal convergence [Collot et al., 1995].

In addition to the record on the sea-floor, Casey and Dewey [1984] have proposed that the evolution of transform plate boundaries into trenches explains many of the features of obducted ophiolites. Orogenic activity at continental margins is often initiated by overthrusting and obduction towards the previously stable margin. This indicates that subduction polarity was away from the continental margin, and that trench nucleation was intra-oceanic. Upon changes in poles of relative plate motion, subduction zones have a strong tendency to initiate within ocean basins by the conversion of preexisting plate boundaries to subduction zones [Casey and Dewey, 1984]. Stern and Bloomer [1992] proposed the Jurassic California arc may have formed in a similar way, subduction was initiated along a transform plate boundary.

Subduction zones probably nucleate at fracture zones because of inherent local lithospheric weakness. However, transform margins have been suggested to evolve into converging margins because of (potentially large) offsets in lithospheric age between opposite sides of the transform fault [Stern and Bloomer, 1992] which provides a substantial force for growing a new subduction zone. One reason Stern and Bloomer [1992] suggested this hypothesis is that the new Marianas subduction zone initiated at about the same time as the Pacific plate change in the direction of motion, $\approx 43 \mathrm{Ma}$ [Engebretson et al., 1985]. However, the change in Pacific plate motion appears to have happened before the nucleation of the Marianas, not after, as would be expected from the Stern and Bloomer [1992] model. Moreover, the descent of slabs within the upper mantle will only slowly change plate speed (and direction) [e.g., Richards and Lithgow-Bertelloni, 1996]. The bend in the Hawaiian-Emperor seamount chain is sharp [Clague and Dalrymple, 1987] implying that plate motion changed within $\sim 1 \mathrm{Myr}$. Later in this paper we show that plates take $\sim 10 \mathrm{Myr}$ to fully change velocity as a new subduction zone initiates. Consequently, the force from increasing slab pull associated with the Marianas subduction zone probably could not cause Pacific plate motion to change abruptly [Richards and LithgowBertelloni, 1996].

The converse of nucleating a converging from a transform margin is also true: preexisting fault zones evolve 
from thrust to strike-slip. Since the Permian, western North America was a converging margin which has progressively evolved into a transform boundary [Atwater, 1970]; at Cape Mendocino, California, the Cascade thrust is directly evolving into the San Andreas transform fault. Presently, the Macquarie ridge is primarily a strike-slip fault, but from at least 61 to $20 \mathrm{Ma}$ it was an active spreading center on the Southeast Indian Ridge which evolved into a transform fault [Cande et al., 1998]. Interestingly, as we have just described, this former spreading center (now a transform fault) is evolving into a zone of convergence with activation of thrust faults within the fault zone immediately south of the South Island of New Zealand [Collot et al., 1995]. The initiation of subduction along the Puysegur ridge is occurring along a segment of a transform plate margin with little offset in age; this supports our hypothesis that subduction zones nucleate on fracture zones because of inherent weakness and not the localization of buoyancy. Clearly, for the Pacific, the largest oceanic plate, converging and strike slip boundaries have lineages related to other faults (Fig. 2).

Evidence for the reactivation of fault zones within the continental crust is substantial [Holdsworth et al., 1997; White, 1976]. For example, at the longest time scale, the Nagssugtoqidian boundary in Greenland, made up of narrow shear zones [Sørensen, 1983], has had intermittent activity over 2.5 Gyr [Watterson, 1975] and the $500 \mathrm{~km}$ long Thabazimbi-Murchinson lineation through the Kaapval craton has had a history of repeated reactivation over more than $2.5 \mathrm{Gyr}$ [Good and De Wit, 1997].

\section{FORMULATING GEODYNAMIC MODELS WITH FAULTS AND WEAK ZONES}

Our discussion demonstrates that faults and converging margins are weak, are actively reused as plate motions evolve, and become dormant only to be reused after considerable time. Weak zones and fault reactivation must have an important influence on plate and mantle dynamics. However, how faults and weak zones should be incorporated into geodynamic models is a much more difficult and unresolved issue. There is a difference of opinion between which of the following approaches is more appropriate: faults and weak zones should arise naturally from the solution of the appropriate equations [Bercovici 1993; 1995; Moresi and Solomatov, 1998; Tackley, 1998] or some minimum level of initial heterogeneity always needs to be incorporated into plate-mantle models (advocated here).
Models of plate-mantle dynamics are one of three types: instantaneous, transient, or long-term evolutionary. In an instantaneous model, the buoyancy forces are incorporated into a domain in which an equation of motion is solved; the results are compared to a present day quantity, such as plate motion, the geoid, or intraplate stress. Transient models couple the equation of motion with the energy equation and the results are dominated by the initial conditions; the models are compared, for example, to plate motion over million year time intervals. Transient models can be used to understand how the evolution of mantle buoyancy influences plate motion (time scales $>10 \mathrm{Myr}$ ) or they can be used to link mantle convection time-scales with the seismological character of plate boundaries (e.g. Section 2). Long term evolutionary models are only conceptualizations but one could imagine coupling the equations of motion and energy with the transport of lithology and strain history so as to generate weak zones which can then survive and be transported.

Considerable effort has been made in recent years at modeling weak zones, including incorporating faults $a$ priori or letting weak zones develop on their own. Using different formulations of preexisting faults, instantaneous and transient mantle flow models have reached a level of tectonic realism allowing some important conclusions concerning the role of weak zones in mantle dynamics to be drawn. Models quantitatively demonstrate that faulted converging plate margins contribute to producing plate tectonic-like motion. Faults have an important influence over outer rise and trench topography in subduction zones and by comparing dynamic models with observed trench depths, constraints can be placed on the absolute magnitude of interplate stress. The forces and fault coupling necessary to initiate subduction at preexisting faults have been determined. Three-dimensional models which include transform and thrust faults show that weak faults and a power law (or instantaneous) rheology interact and are essential in giving rise to plate-like motion.

\subsection{Fault modeling methods}

Since the repeat time of great earthquakes is longer than our modern, instrumental record, it is not known if the boundary between subducting and overriding plates is a fault which changes only slowly on geologic time scales or if a different plane is used during successive earthquakes. The later possibility seems unlikely and the boundary between the two plates is almost certainly thin in proportion to the thickness of the lithosphere. 
Mariana trench

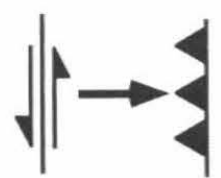

New Guinea to Fiji 然

Macquarie Ridge

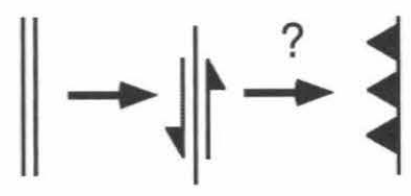

Western N. America $\| \stackrel{?}{\rightarrow}>\rightarrow \mid$

Aleutian trench

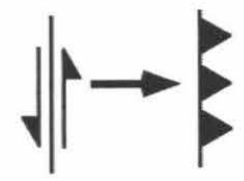

Figure 2. Summary of changes in the character of the active plate boundaries in the Pacific Basin.

Although at depth the interplate coupling surface may be more akin to a shear zone, from the standpoint of formulating models it is convenient to view this structure as a fault - a curvilinear surface over which there are abrupt displacements. Numerical methods have been developed to incorporate the geometric and material complexity of a converging plate boundary (Fig. 1) a narrow fault or shear zone which extends down to $\sim 100 \mathrm{~km}$ depth and curves from shallow dips near the surface to larger dips at depth - into geodynamic models. In all cases, the finite element method [e.g., Hughes, 1987] has been used to model faults in geodynamic contexts within viscous [Zhong and Gurnis, 1992; Barr and Houseman, 1996; Zhong et al., 1998] and viscoelastic [Melosh and Raefsky, 1983; Melosh and Williams, 1989; Toth and Gurnis, 1998] materials.

In seismology, elastic dislocations (faults) have long been used to model the instantaneous deformation associated with earthquakes. In the first geodynamic application, relaxation following large earthquakes was determined in a viscoelastic material [Melosh and Raefsky, 1983]; a split node technique was used in which a single node could have a discontinuous displacement in the elastic field [Melosh and Raefsky, 1981] while subsequently remaining locked as the material deforms viscously. This formulation is ideal for models of the earthquake cycle but not so useful for models of longer term geodynamic processes.

Later, a slippery node technique was introduced, removing the across-fault fixed displacement, so that the fault could subsequently slip as the forces within the continuum evolved [Melosh and Williams, 1989]; in such a model, the geometry of the fault could change as a function of time since the fault was represented with nodes moving with the deforming Lagrangian mesh. Although this approach has been used to model converging margins on mantle convection time-scale [Gurnis et al., 1996] after $\sim 10^{6} \mathrm{yr}$ integration times, the mesh can become extremely contorted with voids opening at the fault tip. To overcome these problems for long integration times, Toth and Gurnis [1998] introduced a method to model a preexisting weak zone as a graded fault with re-meshing. The fault is modeled as a discrete boundary which is defined by a shear stiffness and a normal stiffness. The shear stiffness is effectively the amount of shear coupling between the opposing fault surfaces and controls the shear stress on the fault plane. The shear stiffness increases until the fault becomes fully locked at depth. In this way an abrupt fault tip within the upper mantle is avoided; the relative displacement across the fault gradually decreases to zero with depth as the shear stiffness on the fault increases. The discontinuous brittle deformation is gradationally replaced by continuous viscoelastic strain. In a single model it allows the elastic/brittle nature of lithospheric deformation to be integrated with viscous mantle deformation. Remeshing is essential for long ( $>10^{6} \mathrm{yr}$ ) integration times and an efficient, stable method has been developed for two-dimensional problems [Toth and Gurnis, 1998].

For integration times longer than $10^{6}$ years, viscous formulations have also been used. The Stokes equation appropriate for viscously dominated flows is solved in instantaneous models. Generally, faults are modeled as internal curvilinear surfaces with velocity or stress constraints placed on the fault surface. In viscous formulations where an Eulerian solution to the equations is used, this is not a problem [Zhong and Gurnis, 1995b]. Zhong and Gurnis [1992] introduced faults into a viscous model of mantle flow, assuming that normal velocities vanish on the fault, and showed that oceanic trenches could be formed with the buoyancy force of the slab. The assumption of normal velocities which vanish cannot be justified and subsequently normal velocities were assumed to be continuous while tangential 
velocities discontinuous [Zhong and Gurnis, 1994; 1996; Zhong et al., 1998]. Flow on either side of a fault was coupled through frictional stress. Without the normal velocity constraint, faults nearly always have finite normal velocities. Since trenches rollback [Chase, 1978] (sometimes rapidly, as shown by Bevis et al. [1995] for the Tonga trench), converging margins are unlikely to be in steady-state, and such normal velocities are to be expected. Finite normal velocities are more naturally taken into account in transient calculations of mantle flow where the solution of the momentum and energy equations are coupled - as in any time-dependent model of mantle convection [e.g., McKenzie et al., 1974]. Since faults (having finite normal velocities) are constructed with nodes, faults must be advected. In time-dependent convection models, Zhong and Gurnis [1995b] overcame these aspects with a hybrid Lagrangian Eulerian formulation which was shown to be convergent with migrating fault position and evolving fault geometry.

\subsection{Instantaneous Mantle Flow Models}

The importance of plate driving mechanisms and how mantle rheology influences plate motion, the geoid, and intraplate stress have been addressed with instantaneous models of mantle flow [Hager and O'Connell, 1981; Bott, 1983; Vigny et al., 1991]. In all cases, the strategy is to incorporate the detailed geometry and magnitude of buoyancy forces and then to vary material properties in an effort to find the best fit with geophysical observations (for example). In most studies, plates have been incorporated by assuming a torque balance between plates and mantle flow. Since plates are assumed to be rigid, the existence of plates is guaranteed in torque balance models. Consequently, one of the purposes of developing fault-based methods is to overcome this substantial limitation of torque balances, as the existence of faults by themselves does not guarantee the existence of plates. In fact, we demonstrate that faults and self-weakening (or plastic) rheologies appear to dynamically interact, giving rise to plate-like motion.

A series of representative calculations showing the influence of faults on instantaneous flow are now given. For the buoyancy forces, a half-space cooling thermal boundary layer (within a region, $\mathbf{R}$, for $3 \mathrm{D}$ models) and a cold subducted slab are included (Fig. $3 \mathrm{a}, \mathrm{b}$ ). Outside of $\mathbf{R}$, but excluding the slabs, the thermal structure is identical to the oldest surface age within R. A $100 \mathrm{~km}$ thick slab extends from a depth of $100 \mathrm{~km}$ to $670 \mathrm{~km}$ with a $60^{\circ}$ dip angle. $\mathbf{R}$ is bounded by faults which dissect the upper $100 \mathrm{~km}$ layer, except for the side with the spreading center (Fig. 3a,b). Fault dip is shallow

when the fault is above a slab, but vertical elsewhere. The 2D models can be viewed as cross sections dissecting the 3D models of a subducted slab and spreading center (Fig. 3b).

The viscosity can be a power-law rheology where the effective viscosity, $\eta_{\text {eff }}$, is given by

$$
\eta_{\text {eff }}=A^{1 / n} \dot{\epsilon}^{1 / n-1}
$$

where $n$ is the exponent and is unity for a Newtonian rheology; $A$ is the preexponent depending on temperature, pressure, and composition; $\dot{\epsilon}$ is the second invariant of the strain rate tensor. In the upper mantle

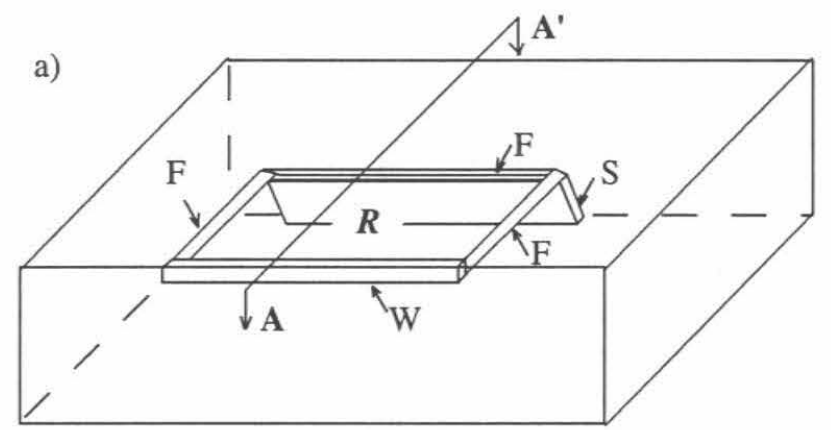

b)
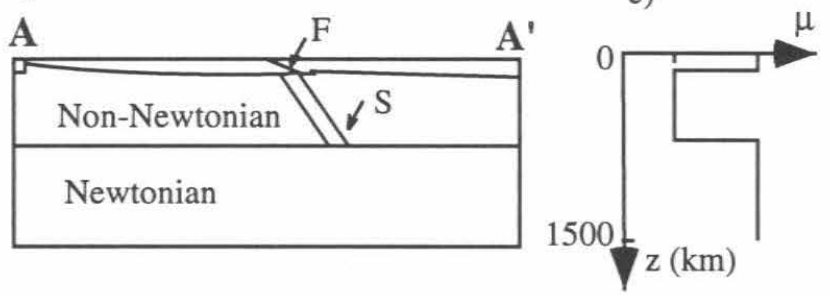

d)

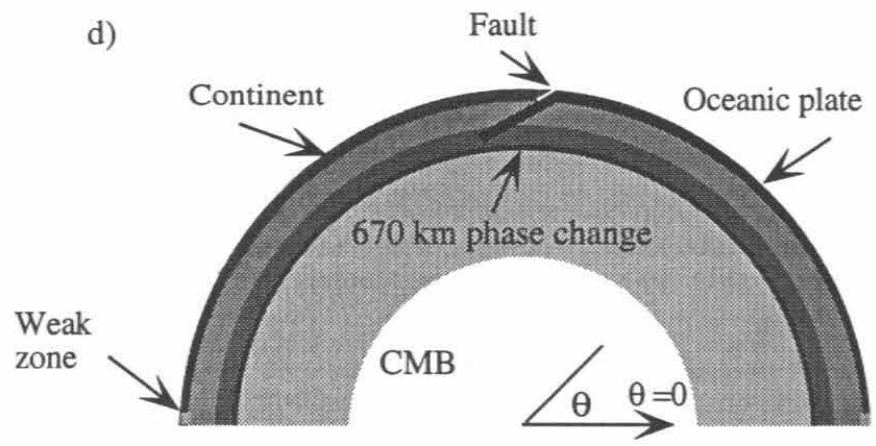

Figure 3. The geometry of the three-dimensional flow model with faults (a), a cross-section AA' of the model for viscosity and thermal structure (b), and the average viscosity profile (c). In (a), F, S, and W label faults, slab, and weak zone, respectively. (d) Setup for the transient mantle convection model in a $2 \mathrm{D}$ cylindrical geometry. 
including the upper $100 \mathrm{~km}, n=3$, while the lower mantle viscosity is Newtonian and equal to $2 \times 10^{22} \mathrm{~Pa}$ s. The power law pre-exponents for slabs and upper $100 \mathrm{~km}$ are larger than other regions so as to implicitly account for a temperature-dependent viscosity. At the spreading center, a narrow region within the upper $100 \mathrm{~km}$ has a smaller pre-exponent in order to account for the higher temperature and partial melting below a ridge. These pre-exponents are chosen so that the average effective viscosities for the upper $100 \mathrm{~km}$ and upper mantle are about $10^{23} \mathrm{~Pa} \mathrm{~s}$ and $2 \times 10^{20} \mathrm{~Pa} \mathrm{~s}$, respectively, and that the average surface velocity in $\mathbf{R}$ is close to the velocity which was used to derive the input buoyancy fields.

5.2.1. Two dimensional models. In order to understand the influence which faults have on instantaneous mantle flow, we begin our discussion with a twodimensional (2D) model which has no faults. The horizontal velocity of the subducting plate is about 1.3 $\mathrm{cm} / \mathrm{yr}$, significantly larger than that of the overriding plate (Fig. 4a,b and Fig. 5a). Within a significant portion of the overriding plate $(\sim 500 \mathrm{~km}$ in width) above the slab, there is a substantial amount of in-plane strain (Fig. 4a,b and 6a); the overriding plate is in a state of a horizontal compression while the subducting plate is in horizontal extension (Fig. 4c). Looking more deeply, the shallow part of the slab is in down-dip extension (Fig. 4c) while at even greater depths (about $500 \mathrm{~km}$ ) the slab is in down-dip compression. Dynamic topography is substantial (about $500 \mathrm{~km}$ in width and 2.4 $\mathrm{km}$ in amplitude) directly above the slab (Fig. 5b). However, this topographic depression above the slab is qualitatively and quantitatively different from oceanic trenches (Plate 1). Oceanic trenches are asymmetrical and substantially narrower in width (about 100-150 km, Plate 1) and deeper, about $4.5 \mathrm{~km}$. In the top $100 \mathrm{~km}$, besides a weak spreading center derived from a reduced exponent, a weak zone also develops above the slab (Fig. $4 \mathrm{a}, \mathrm{b})$. The weak zone above the slab is generated by the nonlinear viscosity which causes the otherwise strong upper $100 \mathrm{~km}$ layer to fail near the large slab induced buoyancy forces. In terms of the top surface horizontal velocity, this model without a fault results in a fairly good plate (termed plateness by Zhong et al. [1998]) in that the horizontal velocity is approximately peicewise uniform (Fig. 5a). However in terms of topography (Fig. 5b), the 'plate boundaries' are substantially more diffuse than they are in reality.

In comparison to the situation just described, a dipping fault has a substantial influence on surface topography and stress and flow within the upper part of the domain. A curved, dipping fault is included in the calculation while all other parameters are identical to the preceding case. There is no resisting shear stress on the fault. With the inclusion of a fault not only does the velocity of the subducting plate double in magnitude (Fig. 5a), but the velocity of this plate becomes substantially larger than that of the overriding plate (Fig 4 e). The subducting plate velocity along the fault is
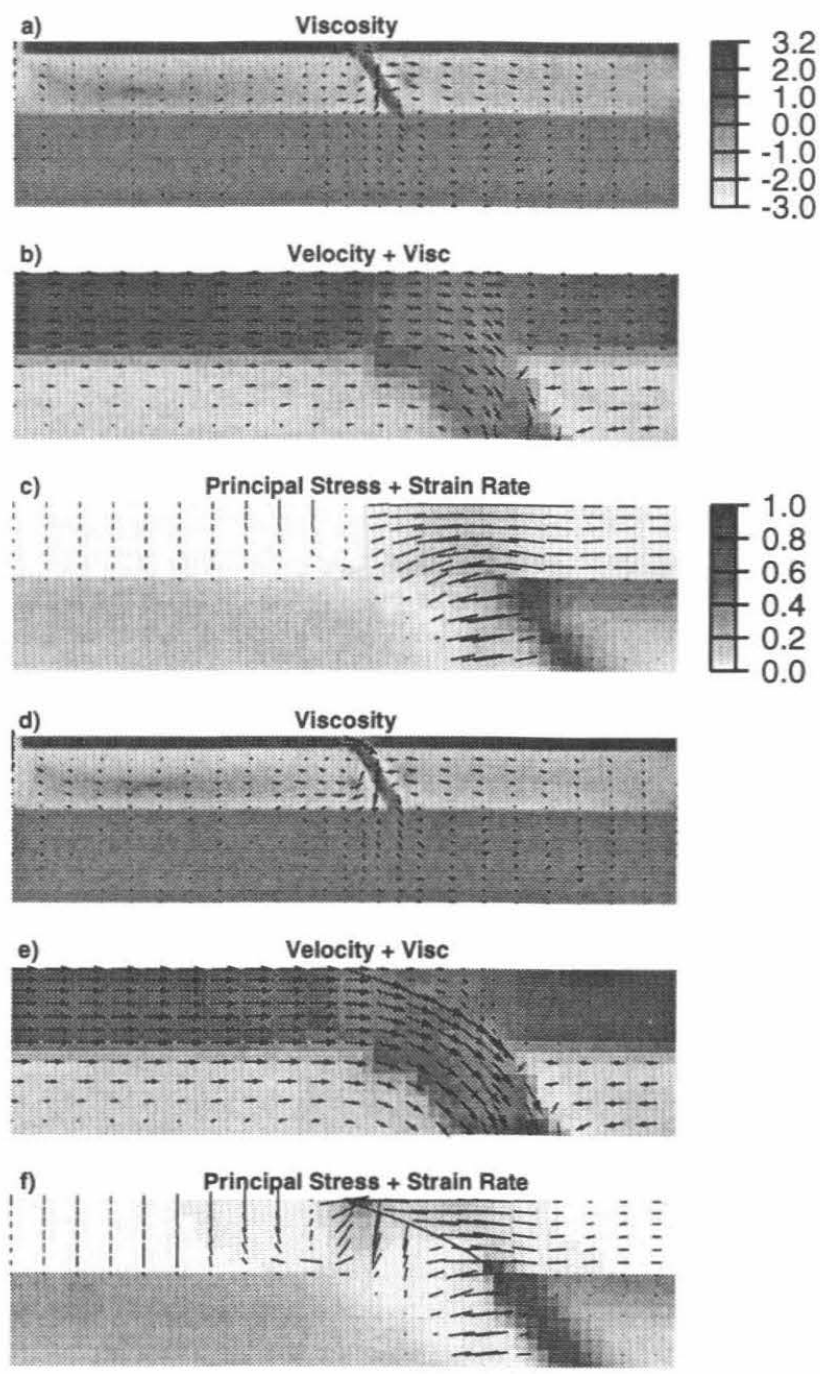

Figure 4. Effective viscosity and flow velocity (vectors) for the entire model domain $(6,000 \mathrm{~km}$ by $1500 \mathrm{~km})(\mathrm{a})$, magnified views in the vicinity of slab show effective viscosity and flow velocity (b) and second invariant of strain rate and principal compressive stress (c) for the $2 \mathrm{D}$ case with no fault. (d), (e), and (f) are for the case with a curved fault. In (c) and (f), the length and orientation of each line represent the magnitude and direction of principal compressive stress. 
nearly parallel to the tangent of the fault (Fig. 4e), although there is still a small, finite normal component. The tangential velocity is discontinuous across the fault, and comparable with the relative motion of convergence between subducting and overriding plates (Fig. 4e and $5 \mathrm{a})$. With a fault, the compressional stress is reduced in the overriding plate (Fig. 4f), compared with the case without a fault (Fig. 4c). Within the subducting plate directly beneath the fault, principal compressional stress is rotated so that it is approximately perpendicular to the fault, and in down-dip extension (Fig. 4f). Assuming an upper mantle viscosity of $4 \times 10^{20} \mathrm{~Pa} \mathrm{~s}$, we find that the average of the second invariant of the stress tensor within the oceanic lithosphere is $\approx 30 \mathrm{MPa}$ and about double that in the forebulge. The rotation of compressional axis perpendicular to faults occurs when there is little to no resisting shear stress on the faults and is similar to the focal mechanism of small earthquakes in the vicinity of interplate faults [Kanamori, 1980; Magee and Zoback, 1993]. Moreover, the downdip extension in the top $100 \mathrm{~km}$ layer is similar to seismic observations of lithospheric earthquakes (Fig. 1) and the average strain rate in the modeled region where the lithospheric earthquakes occur is $\approx 2 \times 10^{-15} \mathrm{~s}^{-1}$ somewhat larger than that inferred from lithospheric earthquakes globally but nearly that inferred for the Japan trench (Section 2). On the oceanic plate and near the fault, the topography is characterized by an outer rise $(\approx 0.4 \mathrm{~km}$ in amplitude and $\approx 200 \mathrm{~km}$ in width $)$ and trench $(\approx 4 \mathrm{~km}$ in amplitude and $\approx 100$ $\mathrm{km}$ in width) - identical to observed trench-forebulge bathymetry. On the overriding plate, topography is elevated near the fault but depressed over the slab (Fig. $5 b)$.

For instantaneous models, these results show that plateness (defined in terms of both a piece-wise uniform horizontal velocity and the topographic sharpness of plate edges), is dramatically improved when faults with low (to nonexistent) shear stress are incorporated. These models demonstrate that trenchforebulge bathymetry can be realistically modeled with buoyancy forces with low deviatoric stresses in the plate - a substantial improvement over the ad-hoc use of displacement and moment arm boundary conditions at the edges of plates which cannot be tied to buoyancy forces. Moreover, flexural models cannot predict plate motions - a primary outcome of a geodynamic model.

5.2.2. Three dimensional models. Three-dimensional models are needed to examine the influence of transform faults and oblique convergence. For comparison, our first case is the $3 \mathrm{D}$ equivalent of our $2 \mathrm{D}$ case containing no faults and with slab strike parallel to the spreading center (Fig. 6a). Surface velocities in region, $\mathbf{R}$, vary gradually in both the spreading parallel and perpendicular directions (Fig. 6b, Fig. 7a,b). The ratio of toroidal to poloidal components of the surface velocity is substantially smaller than for a perfectly rigid plate with this configuration [Zhong et al., 1998]. The effective viscosity of both the diverging and converging "margins" are reduced. The effective viscosity in other surface regions varies gradually, reflecting the variations in strain rate (Fig. 6b). Topography in region, $\mathbf{R}$, increases with age and distance from the spreading center, as expected, but over the slab there is a broad depression ( $~ 500 \mathrm{~km}$ in width) (Fig. 6c), similar to that from the 2D calculations (Fig. 5b) and completely unlike observed trench topography.

We now contrast this with a model that includes faults with zero frictional stress. The strike of the dipping fault is parallel to the spreading center but perpendicular to the strike of vertical faults (Fig. 6d). We find that surface velocity in region, $\mathbf{R}$, bounded by faults is nearly constant (Fig. 6e, 7a,b) and parallel to the
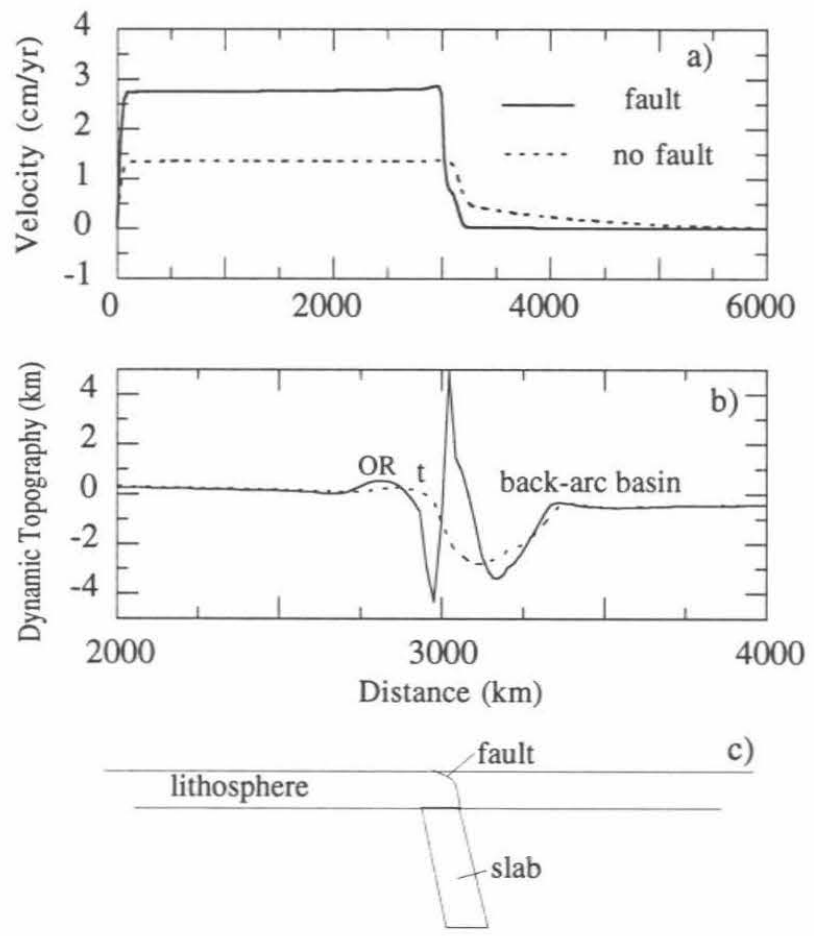

Figure 5. Surface velocity profiles (a) and dynamic topography (b) for the $2 \mathrm{D}$ instantaneous viscous flow models shown in Fig. 4. The surface expression of the fault is at $3,000 \mathrm{~km}$. In b, the following are labeled for the model with no fault (solid curve): outer rise, OR, trench, $t$, and back arc basin. (c) A schematic showing the location of the fault and slab for the profiles in b. 
strike of vertical faults. The velocity contrasts across faults are sharp (Fig. 7a,b). Unlike the case without a fault, the ratio of toroidal to poloidal surface velocities become as large as for a perfectly rigid plate with this geometry [Zhong et al., 1998]. Like the 2D model, an outer rise $(\approx 200 \mathrm{~km}$ in width and $0.4 \mathrm{~km}$ in amplitude) and trench $(\approx 100 \mathrm{~km}$ wide and $4 \mathrm{~km}$ deep) topography develop near the dipping fault (Fig. 6f, 7d). Nonlinear interaction between weak faults and the stress weakening rheology results in the plate-like surface velocity. With these models, we find that weak faults and a stress weakening rheology, and weak coupling between plate and asthenosphere are all necessary in order to achieve the plate-like surface motion and that faults play an important role in producing oblique subduction.

As the frictional resistance of faults increases from 0 to $20 \mathrm{MPa}$, the surface velocity, toroidal to poloidal ratio, and plateness decrease and progressively resemble flow with no faults (Fig. 7a-c). As the magnitude of the absolute shear stress on the fault increases, trench depth decreases (Fig. 7d). In a systematic analysis of trench depth versus age of the subducting plate, fault dip angle, and Benioff zone length and dip, the best fitting interplate stress for ocean-ocean converging margins is about 10-30 MPa [Zhong and Gurnis, 1994], slightly larger than the stress drop of interplate earthquakes [Kanamori, 1980] but within the range estimated from heat flow [Lachenbruch and Sass, 1988].

\subsection{Transient mantle flow models}

Since plate geometry and motion have varied in the past [e.g., Engebretson et al., 1985), time-dependent convection models are needed to address a variety of geophysical questions. One important problem is the relationship between present day mantle structure (seismic tomography) and time-dependent plate kinematics [e.g., van der Hilst and Seno, 1993]. Another set of questions relate to the reason subduction zones initiate where they do and how subduction initiation is related to plate evolution [e.g., Richards and LithgowBertelloni, 1996]. A more complete understanding of the dynamics of subduction initiation is important because it allows us to determine the conditions necessary for subduction to occur (such as the strength of the driving forces) as well as those processes which inhibit subduction growth (such as resisting forces on faults). Moreover, with a better understanding of the timeevolution, predictions can be tested against the tectonic history of a former site of subduction initiation. Since the change in plate geometry must occur through variations in margin geometry, it is essential to formulate models of mantle convection that include plates with dynamically evolving margins. As mentioned in Section 5.2, in the traditional method to model plates, the torque balance approach, a fixed plate geometry must be imposed. With fault methods, these limitations can be overcome.

Time-dependent models using viscous and viscoelastic materials have been setup. For viscoelastic materials, a series of models have been formulated, first, to understand the forces necessary and fault coupling inhibiting subduction initiation and, secondly, to assess how stresses and topography vary as subduction proceeds. A preexisting, dipping fault cuts the lithosphere while the oceanic plate is pushed from the side for $\approx 20 \mathrm{Myr}$ with force boundary conditions. In a similar way, a viscous model is formulated, integrated for $>200 \mathrm{Myr}$, allowing interaction between the evolution of the slab and fault geometry and position. Viscoelastic models of plates and the mantle on $10^{6} \mathrm{yr}$ time-scales allow us to bridge the gap between instantaneous models and longer term, time-dependent models of platemantle convection. The viscous model is entirely selfconsistent in that the buoyancy forces and fault evolve
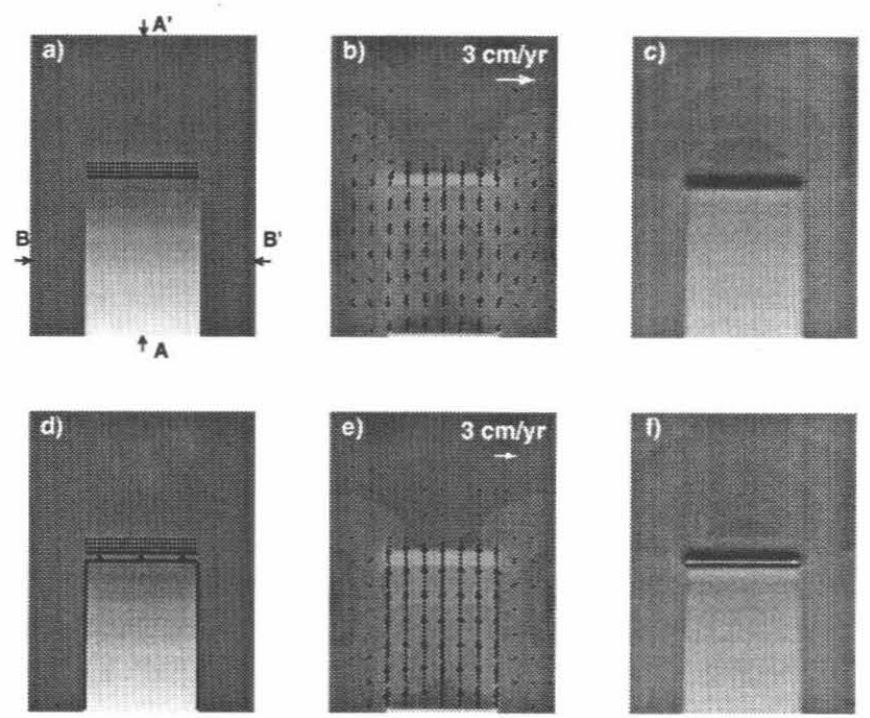

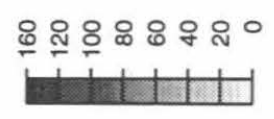

Surface Age (myr)



$\log 10$ (Viscosity)



Topography (km)
Figure 6. The top (a, b, and c) and bottom three panels (d, e, and f) are the mapview of input buoyancy, outputs of surface velocity and effective viscosity, and dynamic topography, for the 3D cases with no fault and with faults, respectively. In (a) and (d), the parallel lines outside $\mathbf{R}$ show the depth of slabs. In (d), the lines bounding $\mathbf{R}$ represent faults; triangles on fault lines indicate a dipping fault. 

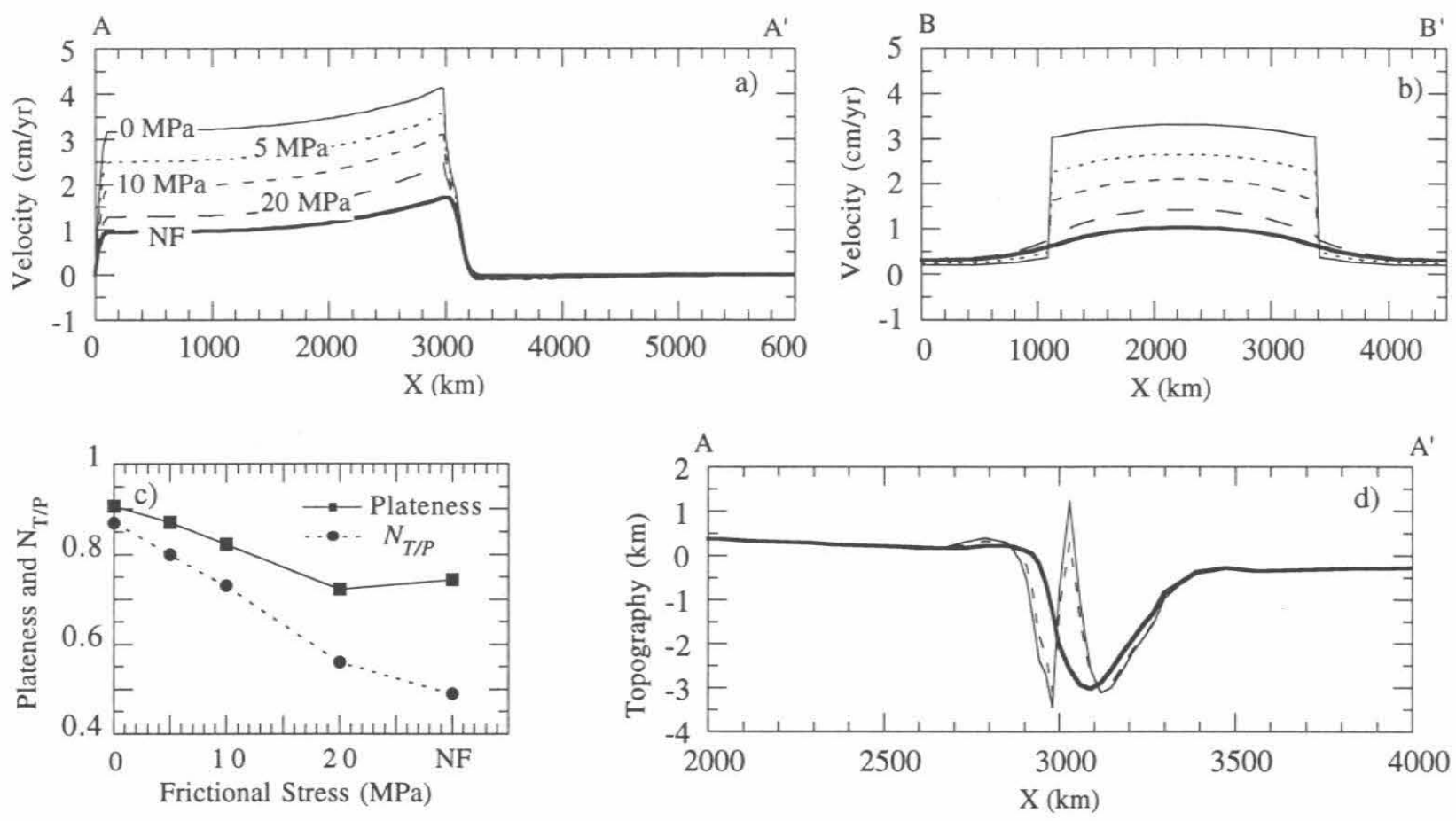

Figure 7. For the 3D models shown in Fig. 6, surface velocities for cross sections AA' (a) and BB' (b), and normalized ratio of toroidal to poloidal components and plateness (c) for cases with no faults (NF) and with faults of different frictional stress. In (d) dynamic topography is shown for the case with no fault as well as for a fault with either a stress of $0 \mathrm{MPa}$ or $10 \mathrm{MPa}$

entirely on their own. The model in the viscoelastic material is not entirely self consistent because part of the force is imposed; however, fault geometry, shape, and position evolve self-consistently.

5.3.1. Viscoelastic models of subduction initiation. Within a newly nucleating subduction zone, profound changes occur at the plate boundary as slab pull comes to dominate the dynamics. Despite a fairly extensive literature, only recently have time-dependent models with realistic geometries and rheologies been computationally possible [Toth and Gurnis, 1998]. We highlight the major results of a detailed study by Toth and Gurnis [1998] in which newly initiating subduction was investigated with velocity and force boundary conditions.

The initiation of subduction in a two-dimensional viscoelastic material is studied for the first $20 \mathrm{Myr}$ of plate convergence for a thermally defined oceanic lithosphere. During the first $\sim 10 \mathrm{Myr}$, using a ridge push appropriate for old oceanic lithosphere $\left(4 \times 10^{12} \mathrm{~N} / \mathrm{m}\right)$ [McKenzie, 1974; Turcotte and Schubert, 1982]), the plate is nearly everywhere in compression, except near the trench which is under extension (Fig. 8a). After $20 \mathrm{Myr}$ of convergence, the slab has reached a depth of nearly $250 \mathrm{~km}$ and the deviatoric compression within the overriding plate, above the fault, has increased to nearly $100 \mathrm{MPa}$. Within the overriding plate, away from the trench, deviatoric stresses change from compression at $5 \mathrm{Myr}$ to extension at $20 \mathrm{Myr}$. Topography, characterized by a distinctive trench and forebulge (Fig. $9 \mathrm{~d})$, grows with time as the buoyancy beneath the fault increases and is qualitatively the same as that which occurs in viscous models. The maximum tensional stress which occurs within the forebulge is only $\approx 200 \mathrm{MPa}$ - substantially smaller than those which occur in elastic or elastic-plastic bending models [e.g., Chapple and Forsyth, 1979].

As the slab lengthens, slab pull and plate velocity increase. For example, with no resistance on the fault and a ridge push of $4 \times 10^{12} \mathrm{~N} / \mathrm{m}$, the velocity of the subducting plate is initially $0.9 \mathrm{~cm} / \mathrm{yr}$, increasing to $2.4 \mathrm{~cm} / \mathrm{yr}$ by $20 \mathrm{Myr}$ (Fig. 9a). With a ridge push of $6 \times 10^{12} \mathrm{~N} / \mathrm{m}$, the initial convergence velocity is 1.4 $\mathrm{cm} / \mathrm{yr}$ (Fig. 9a), but by $20 \mathrm{Myr}$ has increased to nearly $12 \mathrm{~cm} / \mathrm{yr}$ with the slab reaching a depth of $500 \mathrm{~km}$. If the ridge push is reduced to $2 \times 10^{12} \mathrm{~N} / \mathrm{m}$, the initial convergence is only $0.4 \mathrm{~cm} / \mathrm{yr}$ and does not increase substantially with time (Fig. 9a). In terms of the subsurface temperature distribution, the $1200^{\circ} \mathrm{C}$ geotherm 

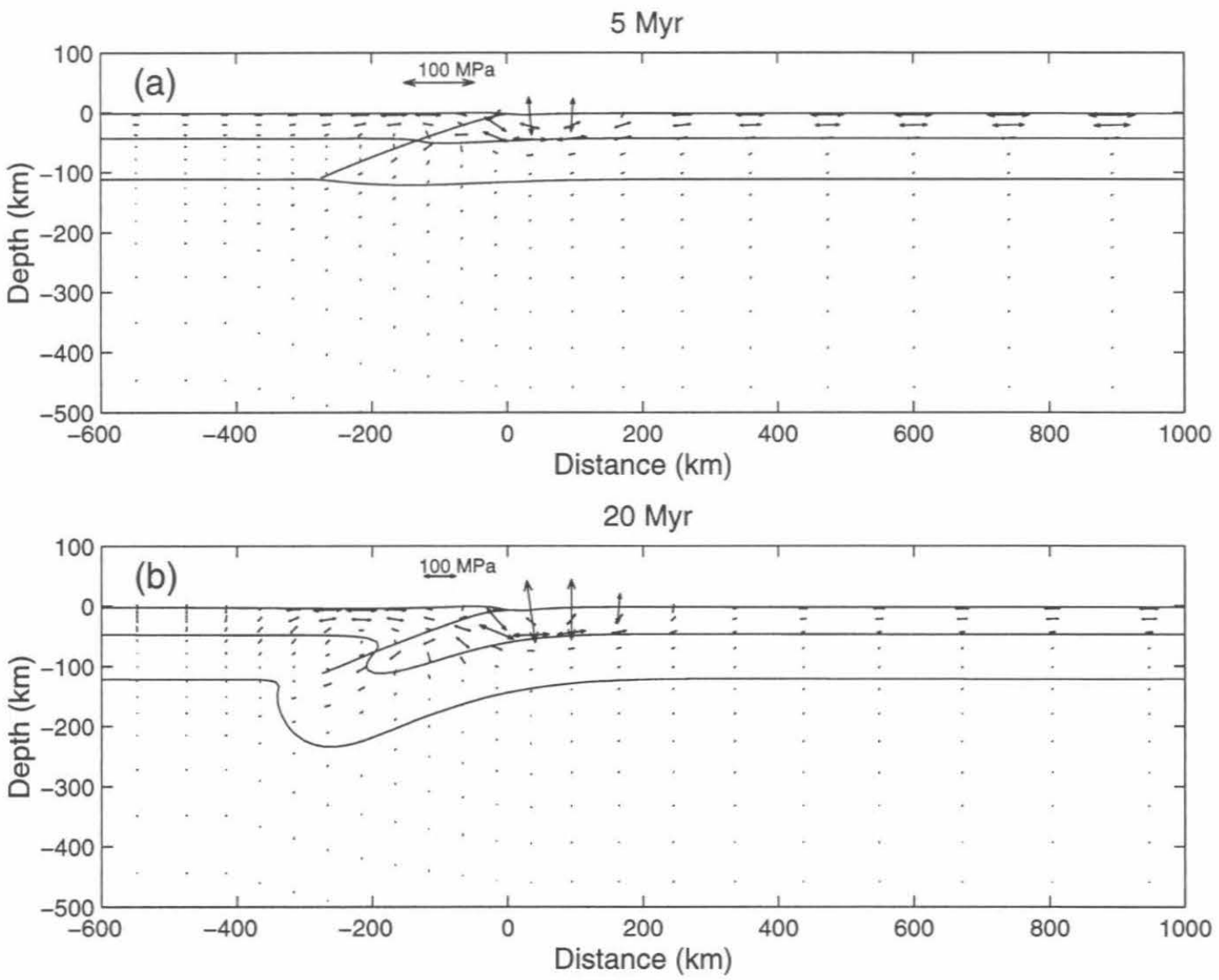

Figure 8. Principal deviatoric compressive stress and isotherms for the model with a constant force boundary of $4 \times 10^{12} \mathrm{~N} / \mathrm{m}$. Isotherms at $600^{\circ}$ intervals. (a) After 5 Myr little convergence has taken place and horizontal compression dominates the stress field within both the overriding and subducting plates. (b) After $20 \mathrm{Myr}$ convergence rate has increased and the slab is now well developed. Down-dip compression is seen within the slab and horizontal extension is seen within the overriding plate away from the trench. Note that these views represent zoom images around the slabs and that the entire model domain was $4,000 \mathrm{~km}$ (width) by $1,000 \mathrm{~km}$ (depth).

has been perturbed downwards by less than $40 \mathrm{~km}$ after $20 \mathrm{Myr}$. Consequently, with this lower ridge push, the rate of convergence is so low that diffusive heating inhibits slab development, and it appears that subduction will not initiate for a significantly longer period of time. For a constant ridge push $\left(6 \times 10^{12} \mathrm{~N} / \mathrm{m}\right)$, when the shear stress on the fault is increased from zero to $8.8 \mathrm{MPa}$, the initial convergence velocity is reduced from $1.4 \mathrm{~cm} / \mathrm{yr}$ to $0.9 \mathrm{~cm} / \mathrm{yr}$ (Fig. $9 \mathrm{~b}$ ). The high shear stress prevents subduction from becoming well established as the convergence velocity after $20 \mathrm{Myr}$ increased to only $1.2 \mathrm{~cm} / \mathrm{yr}$. By observing the history of plate convergence and slab lengthening, Toth and Gurnis [1998] were able to map out the domains of subduction initiation or failed initiation as a function of both plate driving force and interplate coupling (Fig. 10).
5.3.2. Time-dependent mantle convection. The timedependent model of mantle convection which we show is in many ways similar to the suite of viscoelastic models just presented. It includes continental and oceanic plates, separated by a thrust fault with no resisting shear stress (Fig. 3d). This methodology has been used to study the influence of slab and mantle rheology [Zhong and Gurnis, 1995a; 1997] and thermodynamic formulation [Ita and King, 1998] on the history of plate motion and slab structure. An important difference is the inclusion of an endothermic phase change at $670 \mathrm{~km}$ depth. Initially, the fluid interior is isothermal $\left(1600^{\circ} \mathrm{C}\right)$ with a cooling oceanic plate along the surface, zero age at $\theta=0$. The material below the $410 \mathrm{~km}$ depth is assumed to be Newtonian, while the shallower regions, non-Newtonian. Like the instantaneous viscous 

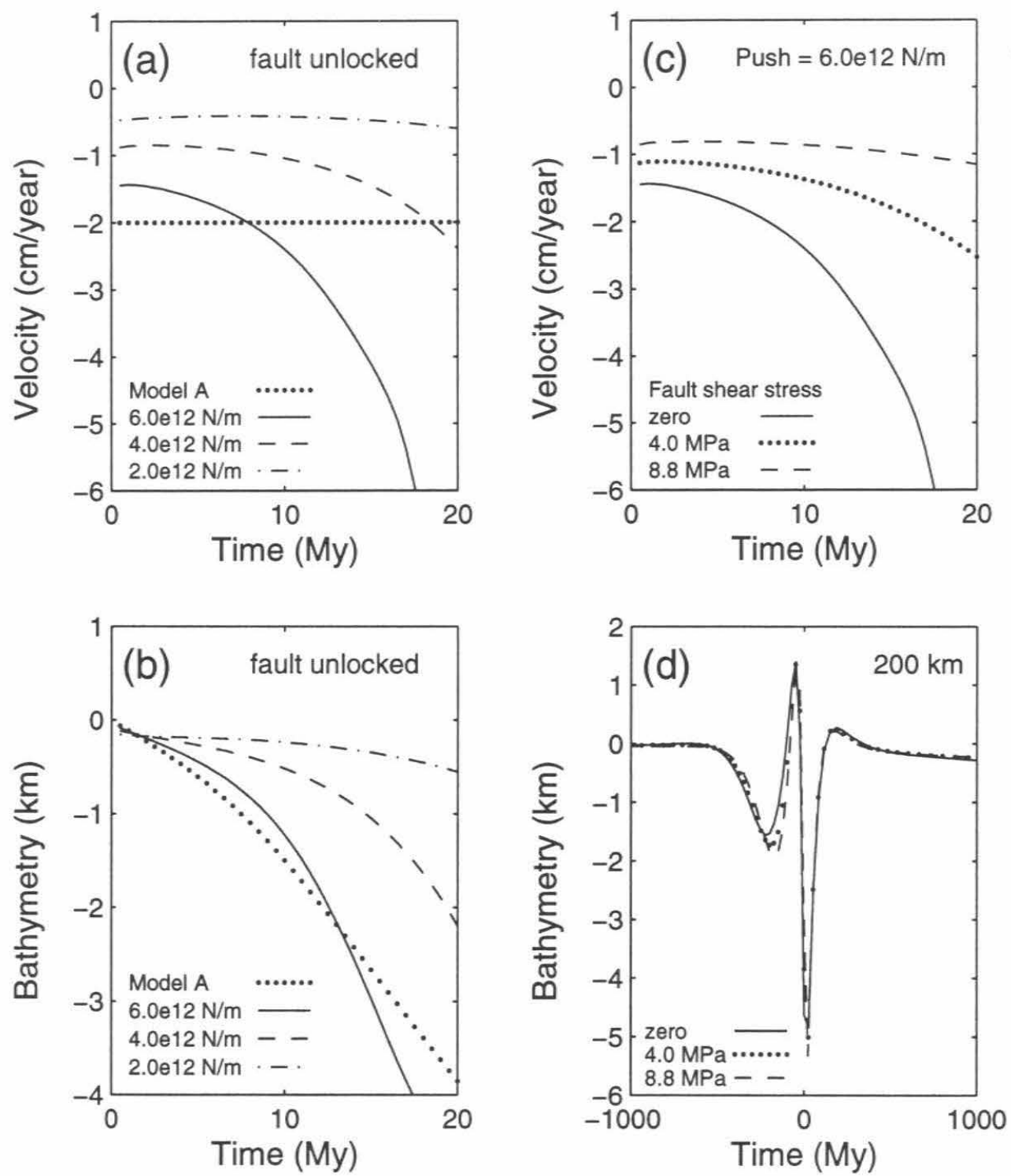

Figure 9. For viscoelastic models: (a) Convergence velocity and (b) bathymetry $250 \mathrm{~km}$ from the trench, for models with different far field forces and as well as model with a constant plate velocity. (c) Convergence velocity and (d) bathymetry after $200 \mathrm{~km}$ of convergence, for models with a far field force of $6 \times 10^{12} \mathrm{~N} / \mathrm{m}$ and different fault shear stresses.

and transient viscoelastic models, non-Newtonian viscosity is critical to the weakening of the oceanic plate as slabs slide by the thrust fault during subduction.

The negative buoyancy of the cooling oceanic plate initiates its own subduction as well as the motion of the continental plate which starts shortly after the model begins (Fig. 11a). Accompanying overriding plate motion, the faulted converging margin moves oceanward (Fig. 12b ) such that the overriding plate increases in size. When the slab encounters the phase change at $670 \mathrm{~km}$ (at $55 \mathrm{Myr}$ ) plate motion is slightly reduced (Fig. 12a). During its initial encounter with the phase change, the slab cannot penetrate below $670 \mathrm{~km}$, and deforms within the transition zone (from $50 \mathrm{Myr}$ to 117 Myr, Fig.11a). During this period, the subducting and overriding plates converge at relatively constant velocity, and the overriding plate increases in size at the expense of the subducting plate. By $\approx 200 \mathrm{Myr}$, the 
length of the overriding plate has increased by more than $2,000 \mathrm{~km}$ (Fig. 12b). The slab now sinks into the lower mantle, apparently after a sufficient mass of cold material has accumulated above the phase change (Fig. 11b) [e.g., Tackley et al., 1993]. As the slab sinks into the lower mantle at $\approx 200 \mathrm{Myr}$ the velocity of the subducting plate increases rapidly, while the velocity of the overriding plate decreases. As the slab reaches the bottom boundary (225 Myr), the velocity of subducting plate gradually decreases to a relatively constant velocity $4.0 \mathrm{~cm} / \mathrm{yr}$.

Plate-like motion is achieved for both overriding and subducting plates (Fig. 11). The overriding plate consists of continental and oceanic components, but they form a single coherent plate (Fig. 11). During the early stages of subduction, the slab is deflected above the 670 $\mathrm{km}$ phase change with a shallow dip angle, while the slab extends beneath the overriding plate by more than $1000 \mathrm{~km}$ (Fig. 11a,b). After the slab penetrates into the lower mantle, the slab has a steep dip (Fig. 11c). When the slab is deflected above the $670 \mathrm{~km}$, the trench tends to migrate at a larger rate. However, when the slab penetrates into the lower mantle, the horizontal motion of the trench ceases (Fig. 12a). One of the most important conclusions of these models is the clear association between plate kinematics and the structure of subducted slabs. Moreover, slab penetration into the lower mantle is time-dependent and sometimes ephemeral.

\section{DISCUSSION AND CONCLUSIONS}

Two important lithospheric properties motivate mantle convection models with non-Newtonian viscosity and preexisting faults. First, subducting oceanic lithosphere below trenches has a relatively small mechanical strength compared with normal oceanic lithosphere. Second, plate margins are weak not only because there is continuous brittle failure of oceanic lithosphere (instantaneous rheology), but because the lithosphere preserves weak faults and shear zones for long periods (often $>1$ Gyr) of geologic time (history dependent rheology). Ultimately, these two mechanisms by which low mechanical strength is carried by the lithosphere is crucial for understanding how plate dynamics operates and how plate tectonics is formed from mantle convection.

As the oceanic lithosphere slides by the interplate coupling zone, it is normally thought of as being fairly strong as indicated by the outer rise which bears similarities to flexural bulges around oceanic islands. Even the elastic-perfectly plastic bending model assumes that the core of the oceanic lithosphere supports the outer rise



Figure 10. Comparison of theoretical prediction of the boundary between domains of subduction initiation and no initiation. Shear stresses on preexisting faults from three different estimates are indicated: from large interplate earthquakes, from heat flow on San Andreas fault, and from trench depths.

elastically [McAdoo et al., 1978; Chapple and Forsyth, 1978]. We argued that there are three reasons to question this paradigm: the occurrence of lithospheric earthquakes which completely fracture the oceanic lithosphere, the space-time occurrence of outer rise earthquakes which demonstrate that the outer rise is a dynamic feature, and the ability to dynamically generate trench-forebulge bathymetry with no elastic strength at all. We have poor constraints on the strain rate and effective viscosity of the trench environment, but it could have a strain rate as high as that within the upper mantle. However, it has long been known that the elastic bending model of the oceanic lithosphere, the principle argument in support of strong margins, is not unique and dynamic support of the outer rise within a weak lithosphere is possible (Fig. 5, 7).

Interplate fault zones are weak as suggested by earthquake stress drops, heat flow near faults, and the orientation of small earthquakes near interplate faults. From the geologic history of oceans and continents there are numerous examples showing how fault zones have been reactivated from transform to convergence, from convergence to transform, and from divergence to strike-slip. The time-scale between formation and reactivation can exceed a few gigayears and there are examples of reactivation on all time-scales of shorter duration. 


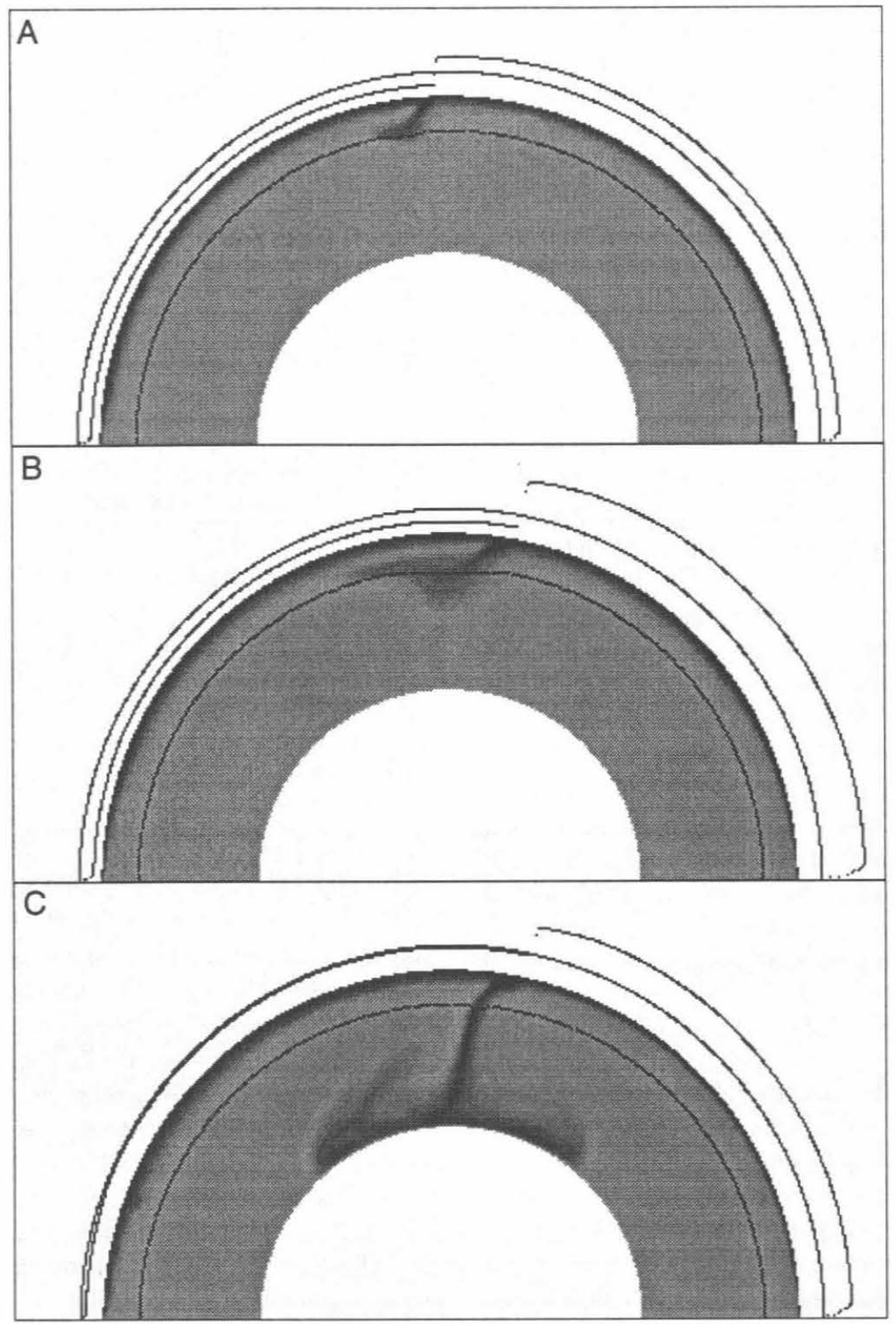

Figure 11. Thermal structure and surface plate velocity (solid line) resulting from the transient mantle convection model at three different times (a), (b), and (c). The dashed line indicates the zero velocity. The solid line within the fluid interior indicates the $670 \mathrm{~km}$ phase change.

This substantial body of geophysical and geological knowledge motivated the incorporation of preexisting faults in models of instantaneous and time-dependent mantle convection from which a number of fundamental conclusions can be drawn. With a realistic distribution of buoyancy forces within either viscous or viscoelastic materials the distinctive trench forebulge morphology easily develops. Without the ad-hoc displacement and moment arm boundary conditions on elastic plates which have long been used to curve fit bathymetry near a trench, we are able to get a nearly perfect model of the trench and forebulge. The absolute magnitudes of trench depth and plate velocity, both unobtainable with traditional flexure models, can both be predicted with the new methods with preexisting faults and realistic slab buoyancy. 

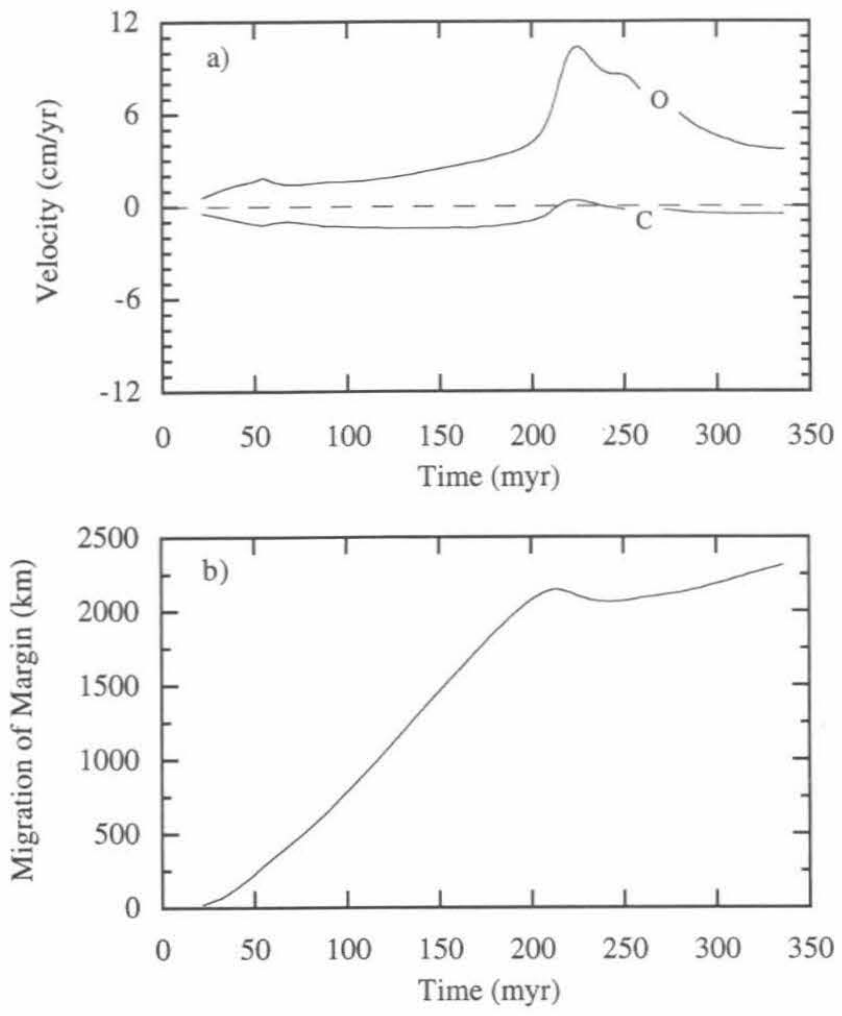

Figure 12. Time history of plate velocities (a) and trench migration (b) for the convection model shown in Fig. 11. Symbols $\mathrm{O}$ and $\mathrm{C}$ in (a) indicate the velocities of oceanic and continental plates, respectively. The dashed line in (a) indicates zero velocity.

A new subduction zone can initiate at a preexisting fault with reasonable ridge push and slab pull forces. For a ridge push of $4 \times 10^{12} \mathrm{~N} / \mathrm{m}$ subduction initiates even with a fault shear stress of $3 \mathrm{MPa}$, the resistance most consistent with seismological observations. Subduction will not initiate by ridge push alone when this fault shear stress is greater than $5 \mathrm{MPa}$. However, when the Marianas and Aleutian subduction zones were forming, for example, the total force available to initiate subduction would have have been substantially larger than ridge push alone because of the force from subducted slabs attached to other parts of the Pacific plate. In this case, even with an interplate coupling estimated from dynamic models $(10-30 \mathrm{MPa})$ subduction zones at preexisting faults could easily have formed (e.g. Fig. 10). Unfortunately, our estimate for the minimum forces necessary to initiate subduction is not a conservative one as it is likely that additional work will be needed to evolve a vertical fault zone into a dipping one. A challenge for the future will be the development of models to follow the evolution of a transform fault zone into a thrust fault zone. This process is apparently presently occurring at the Puysegur ridge and trench at the northern end of the Macquarie ridge complex with the development of reverse faults along the transform fault [Collot et al., 1995]. It is likely that models can be tailored to this region to better understand this vital, but poorly understood, phase of the plate tectonic cycle.

With both the viscous and viscoelastic models, plate velocity only slowly increases with time. It is essential for us to determine the means by which a plate can increase in velocity by a few $\mathrm{cm} / \mathrm{yr}$ in less than 1 Myr (a dramatic acceleration), as indicated by the bend in the Hawaiian-Emporer seamount chain. The modeling shows that during the initiation of subduction, the rate at which plate velocity accelerates increases with the driving force but decreases with interplate coupling. A lower bound on the time-scale at which plate velocity can dramatically accelerate has not been well determined but it is unlikely to be substantially smaller than $10 \mathrm{Myr}$ if plate velocities are less than $\sim 10 \mathrm{~cm} / \mathrm{yr}$. From the history of modeled plate convergence, it takes $>10 \mathrm{Myr}$ for convergence to reach appreciable levels (a few $\mathrm{cm} / \mathrm{yr}$ ). This supports the contention that plate motion cannot quickly reorganize as new subduction zones form [Richards and Lithgow-Bertelloni, 1996].

We have developed 3D models with non-Newtonian viscosity and preexisting faults and are able to obtain realistic plate tectonic-like motion and realistic plate margin topography. Bercovici [1993] and Tackley [1998] have addressed this problem using a different rheology. The importance of rheology is shown by looking at how rheologies have been incorporated into dynamic plate models. A 'stick-slip' rheology, a highly nonlinear viscous rheology where $n=-1$, equation 2 , has been used by Bercovici [1993] and Tackley [1998]. When $n=-1$, only a finite deviatoric stress can be supported as strain rate increases and for strain rates beyond some critical value, stress decreases. This rheology approximates the brittle failure of rocks with a viscous rheology and has been referred to as self-weakening or strain rate weakening; it is an example of what we call an instantaneous rheology. Using this rheology, Bercovici [1983] modeled plates in instantaneous flows with sources and sinks within a thin sheet; Tackley [1998] later extended the approach to 3D with more realistic internal buoyancy forces. They found that weak plate margins formed above upwellings and downwellings and within localized narrow shear bands (akin to transform faults) between upwellings and downwellings. Since the generation of 
weakness is proximal to downwellings we believe that this aspect of their models is akin to continuous brittle failure, which we document within the trench environment (Section 2). The sites of the greatest amount of present day brittle failure within oceanic lithosphere are not arbitrarily located, but rather occur in close proximity to long lived zones of preexisting weakness. We believe that the sole use of self-weakening rheologies is not adequate to model instantaneous plates because the weak zones in the Bercovici [1993] and Tackley [1998] models develop instantaneously within an intact medium directly in response to imposed forces. The generation of plate margins in these models from an intact lithosphere is not consistent with the geologic evolution of oceanic plate margins since the Mesozoic (Section 4).

More specifically, Bercovici [1995] applied the self weakening rheology to present day plate motion using a thin viscous spherical shell with sources and sinks of flow determined from observed divergence and convergence. He was able to reproduce plate motion with these constraints when a strain softening rheology was used. In these models, the weak zones form directly in response to the forces. For example, the Mariana, Macquarie Ridge, and Aleutian margins of the Pacific (as other plate margins) are weak in Bercovici's [1995] model; however, we have detailed the geological evolution of these regions (as well as other regions) and have shown that the locations of these margins are inherited from preexisting structures.

Furthermore, we believe that the sole incorporation of self-weakening rheologies in time dependent models of mantle convection (technically not yet achieved) in order to simulate time-dependent plate dynamics should be approached with caution. The time-dependence of mantle convection is strongly governed by the reactivation of preexisting structures. A model with only an instantaneous rheology would not be able to nucleate new plate margins in regions away from localized buoyancy forces or active plate margins. Consequently, the incorporation of history dependent rheology is essential for time-dependent models. This need for history-dependent rheology and preexisting structures motivated our development of fault methodologies. However, even these fault methods have their own limitations as they are only appropriate for transient convection calculations tailored to address specific geologic questions.

The geophysical and geological observations described here and instantaneous and transient convection models with preexisting faults suggest a complicated process for the normal evolution of plate motions - continuous brittle failure of lithosphere dynamically interacts with preexisting faults. Once a plate boundary forms, this region creates a new weak zone which later may become dormant. The lithosphere will then carry (retain) this dormant weak zone for long periods of time. The dormant structure will be the site of a new plate boundary which may be quite different from the one which it originally nucleated as. The transient models of mantle convection we have formulated do not yet approach this full treatment of the creation of mechanical weakness within the lithosphere, dormancy, and later reactivation. Without substantial modifications, it is unlikely that fault methods developed for transient models of mantle convection can be used for this purpose. A challenge for the future will be to couple the equations of motion and energy with the transport of lithology and strain history so as to generate weak zones which can survive, be transported, and be reactivated.

Acknowledgments. We thank Hiroo Kanamori for many discussions and unpublished information on lithospheric earthquakes. This work was supported by NSF grants EAR9417645 and EAR-9614391. Some of the 3D models with faults were carried out on the Intel Paragon supercomputer operated by the Caltech Center for Advanced Computer Research (CACR). This represents Contribution Number 8578 of the Division of Geological and Planetary Sciences, California Institute of Technology.

\section{REFERENCES}

Artyushkov, E. V., Stresses in the lithosphere caused by crustal thickness inhomogeneities, J. Geophys. Res., 78, 7675-7708, 1973.

Atwater, T., Implications of plate tectonics for the Cenozoic tectonic evolution of western North America, Geol. Soc. Am., Bull., 81, 3513-3536, 1970.

Barr, T. D., and G. A. Houseman, Deformation fields around a fault embedded in a non-linear ductile medium, Geophys. J. Int., 125, 473-490, 1996.

Ben-Avraham, Z., and S. Uyeda, Entrapment origin of marginal seas, in Geodynamics of the Western PacificIndonesian Region, edited by T. Hilde and S. Uyeda, pp. 91-104. Am. Geophys. Un., Washington, 1983.

Bercovici, D., A simple model of plate generation from mantle flow, Geophys. J. Int., 114, 635-650, 1993.

Bercovici, D., A source-sink model of the generation of plate tectonics from non-Newtonian mantle flow, J. Geophys. Res., 100, 2013-2030, 1995.

Bercovici, D., Y. Ricard, and M. A. Richards, The relation between mantle dynamics and plate tectonics: A primer, in History and Dynamics of Global Plate Motions, edited by M. A. Richards, R. Gordon and R. Van der Hilst, Geodynamic Series. Am. Geophys. Un., this volume, 1999.

Bevis, M., Seismic slip and down-dip strain rates in WadaticBenioff zones, Science, 240, 1317-1319, 1988. 
Bevis, M., et al., Geodetic observations of very rapid convergence and back-arc extension at the Tonga trench, $\mathrm{Na}$ ture, 374, 249-251, 1995.

Bott, M. H. P., Modelling the plate-driving mechanism, $J$. Geol. Soc. Lond., 150, 941-951, 1993.

Cande, S. C., J. Stock, C. Raymond, and D. R. Müller, New constraints on plate tectonic puzzle of the SW Pacific, EOS, Trans. Am. Geophys. Un., 79, 81-82, 1998.

Casey, J. F., and J. F. Dewey, Initiation of subduction zones along transform and accreting plate boundaries, triple junction evolution, and forearc spreading centres - implications forophiolitic geology and obduction, in Ophiolites and Oceanic Lithosphere, edited by I. G. Gass, S. J. Lippard and A. W. Shelton, 13, Spec. Pub., pp. 269-290. Geol. Soc. Am., 1984.

Chapple, W. M., and D. W. Forsyth, Earthquakes and bending of plates at trenches, J. Geophys. Res., 84, 6729-6749, 1979.

Chase, C. G., Extension behind island arcs and motions relative to hot spots, J. Geophys. Res., 83, 5385-5387, 1978.

Christensen, D. H., and L. J. Ruff, Seismic coupling and outer rise earthquakes, J. Geophys. Res., 93, 13421-13444, 1988.

Clague, D. A., and G. B. Dalrymple, Geologic evolution of the Hawaiian-Emporer volcanic chain, U.S. Geol. Surv. Prof. pap., 1350, 5-54, 1987.

Collot, J.-Y., G. Lamerche, R. A. Wood, J. Delteil, M. Sosson, J.-F. Lebrun, and M. F. Coffin, Morphostructure of an incipient subduction zone along a transform plate boundary: Puysegur ridge and trench, Geology, 23, 519$522,1995$.

Conrad, C. P., and B. H. Hager, Effects of plate bending and fault strength at subduction zones on plate dynamics, $J$. Geophys. Res., in press, 1999.

Cooper, A. K., D. W. Scholl, and M. S. Marlow, Plate tectonic model for the evolution of the eastern Bering Sea Basin, Geol. Soc. Am. Bull., 87, 1119-1126, 1976.

Davies, G. F., and M. A. Richards, Mantle convection, J. Geol., 100, 151-206, 1992.

DeBremaecker, J.-C., Is the oceanic lithosphere elastic or viscous?, J. Geophys. Res., 82, 2001-2004, 1977.

Engebretson, D. C., A. Cox, and R. G. Gordon, Relative motions between oceanic and continental plates in the Pacific basin, Geol. Soc. Am. Sp. Paper, 205, 1-59, 1985.

Good, N., and M. De Wit, The Thabazimbi-Murchison Lineameant of the Kaapvaal Craton, South Africa: $2700 \mathrm{Ma}$ of episodic deformation, J. Geol. Soc., Lond., 154, 93-97, 1997.

Gurnis, M., C. Eloy, and S. Zhong, Free-surface formulation of mantle convection, part 2: Implication for subduction zone observables, Geophys. J. Int., 127, 719-727, 1996.

Gurnis, M., R. D. Müller, and L. Moresi, Dynamics of Cretaceous vertical motion of Australia and the AustralianAntarctic discordance, Science, 279, 1499-1504, 1998.

Hager, B. H., and R. J. O'Connell, A simple global model of plate dynamics and mantle convection, J. Geophys. Res., 86, 4843-4867, 1981.

Holdsworth, R. E., C. A. Butler, and A. M. Roberts, The recognition of reactivation during continental deformation, J. Geol. Soc., Lond., 154, 73-78, 1997.

Hughes, T. J. R., The Finite Element Method: Linear
Static and Dynamic Finite Element Analysis, PrenticeHall, Inc., Englewood Cliffs, New Jersey, 1987.

Imber, J., R. E. Holdsworth, C. A. Butler, and G. E. Lloyd, Fault-zone weakening processes along the reactivated Outer Hebrides Fault Zone, J. Geol. Soc., Lond., 154, 105-109, 1997.

Ita, J., and S. D. King, The influence of thermodynamic formulation on simulations of subduction zone geometry and history, Geophys. Res. Lett., 25, 1463-1466, 1998.

Jaroslow, G. E., G. Hirth, and H. J. B. Dick, Abyssal peridotite mylonites: implications for gran-size sensitive flow and strain localization in the oceanic lithosphere, Earth Planet. Sci. Lett., 256, 17-37, 1996.

Jarrard, R. D., Relations among subduction parameters, Rev. Geophys., 24, 217-284, 1986.

Jeffreys, H., The Earth, Cambridge University Press, New York, 1970.

Kanamori, H., Seismological evidence for a lithospheric normal faulting-the Sanriku earthquake of 1933, Phys. Earth Planet. Int., 4, 289-300, 1971.

Kanamori, H., State of stress in the Earth's lithosphere, in Physics of the Earth's Interior, edited by A. Dziewonski and E. Boschi, pp. 531-554. North-Holland, Amsterdam, 1980.

Kanamori, H., Rupture process of subduction-zone earthquakes, Ann. Rev. Earth Planet. Sci., 14, 293-322, 1986.

Kanamori, H., Mechanics of earthquakes, Ann. Rev. Earth Planet. Sci., 22, 207-237, 1994.

Kanamori, H., and L. Astiz, The 1983 Akita-Oki Earthquake $\left(M_{w}=7.8\right)$ and its implications for systematics of subduction earthquakes, Earthq. Predict. Res., 3, 305-317, 1985.

Kikuchi, K., and H. Kanamori, The Shikotan earthquake of October 4, 1994: Lithospheric earthquake, Geophys. Res. Lett., 22, 1025-1028, 1995.

Kohlstedt, D. L., B. Evans, and S. J. Mackwell, Strength of the lithosphere: Constraints imposed by laboratory experiments, J. Geophys. Res., 100, 17,587-17602, 1995.

Lachenbruch, A. H., and J. H. Sass, The stress heat flow paradox and thermal results from Cajon Pass, Geophys. Res. Lett., 15, 981-984, 1988.

Magee, M. E., and M. D. Zoback, Evidence for a weak interplate thrust fault along the northern Japan subduction zone and implications for the mechanics of thrust faulting and fluid expulsion, Geology, 21, 809-812, 1993.

McAdoo, D. C., J. G. Caldwell, and D. L. Turcotte, On the elastic-perfectly plastic bending of the lithosphere under generalized loading with application to the Kuril trench, Geophys. J. Roy. Astr. Soc., 54, 11-26, 1978.

McConnell, R. B., Geological development of the rift system of eastern Africa, Geol. Soc. Amer. Bull., 83, 2549-2572, 1972.

McKenzie, D. P., The initiation of trenches: A finite amplitude instability, in Island Arcs Deep Sea Trenches and Barck-Arc Basins, edited by M. Talwani and W. C. Pitman, 1, Maurice Ewing Series, pp. 57-61. Am. Geophys. Un., Washington, 1977.

McKenzie, D. P., J. M. Roberts, and N. O. Weiss, Convection in the Earth's mantle: towards a numerical simulation, J. Fluid Mech., 62, 465-538, 1974.

Melosh, H. J., Dynamic support of the outer rise, Geophys. Res. Lett., 5, 321-324, 1978.

Melosh, H. J., and A. Raefsky, A simple and efficient method 
for introducing faults into finite elment computations, Bull. Seismo. Soc. Am., 71, 1391-1400, 1981.

Melosh, H. J., and A. Raefsky, Anelastic response of the Earth to a dip slip earthquake, J. Geophys. Res., 88, 515$526,1983$.

Melosh, H. J., and C. A. Williams, Mechanics of graben formation in crustal rocks: A finite element analysis, $J$. Geophys. Res., 94, 13,961-13,973, 1989.

Moresi, L., and V. Solomatov, Mantle convection with a brittle lithosphere: Thoughts on the global tectonic styles of the Earth and Venus, Geophys. J. Int., 133, 669-682, 1998.

Müller, R. D., U. R. Roest, J.-Y. Royer, L. M. Gahagan, and J. G. Sclater, Digital isochrons of the world's ocean floor, J. Geophys. Res., 102, 3211-3214, 1997.

Richards, M. A., and C. Lithgow-Bertelloni, Plate motion changes, the Hawaiian-Emperor bend, and the apparent success and failure of geodynamic models, Earth Planet. Sci. Lett., 137, 19-27, 1996.

Sandwell, D. T., and W. H. F. Smith, Marine gravity anomaly from ERS-1, Geosat and satellite altimetry, $J$. Geophys. Res., 102, 10,039-10,045, 1997.

Scholl, D. W., T. L. Vallier, and A. J. Stevenson, Terrane accretion, production, and continental growth: A perspective based on the origin and tectonic fate of the AleutianBering Sea region, Geology, 14, 43-47, 1986.

Sørensen, K., Growth and dynamics of the Norde Strømfjord shear zone, J. Geophys. Res., , 88, 3419-3437, 1983.

Stern, R. J., and S. H. Bloomer, Subduction zone infancy: Examples from the Eocene Izu-Bonin-Mariana and Jurassic California arcs, Geol. Soc. Am. Bull., 104, 1621-1636, 1992.

Sykes, L. R., Intraplate seismicity, reactivation of preexisting zones of weakness, alkaline magmatism, and other tectonism postdating continental fragmentation, Rev. Geophys., 16, 621-688, 1978.

Tackley, P. J., Self-consistent generation of tectonic plates in three-dimensional mantle convection, Earth Planet. Sci. Lett., 157, 9-22, 1998.

Tackley, P. J., The quest for self-consistent generation of plate tectonics in mantle convection models, in History and Dynamics of Global Plate Motions, edited by M. A. Richards, R. Gordon and R. Van der Hilst, Geodynamic Series. Am. Geophys. Un., this volume, 1999.

Tackley, P. J., D. J. Stevenson, G. A. Glatzmaier, and G. Schubert, Effects of an endothermic phase transition at $670 \mathrm{~km}$ depth in a spherical model of convection in the Earth's mantle, Nature, 361, 699-704, 1993.

Toth, J., and M. Gurnis, Dynamics of subduction initiation at pre-existing fault zones, J. of Geophys. Res., 103, $18,053-18,067,1998$.

Turcotte, D. L., and E. R. Oxburgh, Finite amplitude convection cells and continental drift, J. Fluid Mech., 28, 29$42,1967$.

Turcotte, D. L., and G. Schubert, Geodynamics, Wiley, New York, 1982.

Uyeda, S., and Z. Ben-Avraham, Origin and development of the Philippine Sea, Nature Phys. Sci., 240, 176-178, 1972.

Uyeda, S., and H. Kanamori, Back-arc opening and the mode of subduction, J. Geophys. Res., 84, 1049-1061, 1979.

van der Hilst, R., and T. Seno, Effects of relative plate motion on the deep structure and penetration depth of slabs below the Izu-Bonin and Mariana island arcs, Earth Planet. Sci. Lett., 120, 395-407, 1993.

Vigny, C., Y. Ricard, and C. Froidevaux, The driving mechanism of plate tectonics, Tectonophysics, 187, 345-360, 1991.

Vissers, R. L. M., M. R. Drury, E. H. Hoogerduijn Strating, C. J. Spiers, and D. van der Wal, Mantle shear zones and their effect on lithosphere strength during continental breakup, Tectonophysics, 249, 155-171, 1995.

Watterson, J., Mechanism for the persistence of tectonic lineaments, Nature, 253, 520-52, 1975.

White, S. H., The effects of strain on microstructures, fabrics, and deformation mechanisms in quartzites, Phil. Trans. R. Soc. Lond. A, 283, 69-86, 1976.

White, S. H., and P. F. Green, Tectonic development of the Alpine fault zone, New Zealand: A fission track study, Geology, 14, 124-127, 1986.

Wilson, J. T., Did the Atlantic close and then re-open?, Nature, 211, 676-681, 1966.

Zhong, S., and M. Gurnis, Viscous flow model of a subduction zone with a faulted lithosphere: Long and short wavelength topography, gravity, and geoid, Geophys. Res. Lett., 19, 1891-1894, 1992.

Zhong, S., and M. Gurnis, Controls on trench topography from dynamic models of subducted slabs, J. Geophys. Res., 99, 15,683-15,695, 1994.

Zhong, S., and M. Gurnis, Mantle convection with plates and mobile, faulted plate margins, Science, 267, 838-843, 1995a.

Zhong, S., and M. Gurnis, Towards a realistic simulation of plate margins in models of mantle convection, Geophys. Res. Lett., 22, 981-984, 1995b.

Zhong, S., and M. Gurnis, Interaction of weak faults and Non-Newtonian rheology produces tectonic plates in $3 \mathrm{D}$ model of mantle flow, Nature, 383, 245-247, 1996.

Zhong, S., and M. Gurnis, Dynamic interaction between tectonic plates, subducting slabs, and the mantle, Earth Interactions, 1(6), http://EarthInteractions.org/, 1997.

Zhong, S., M. Gurnis, and L. Moresi, The role of faults, nonlinear rheology, and viscosity structure in generating plates from instantaneous mantle flow models, J. Geophys. Res., 103, 15,255-15,268, 1998.

Zoback, M. D., and J. H. Healy, In situ stress measurements to $3.5 \mathrm{~km}$ depth in the Cajon Pass scientific resaerch borehole: Implications for the mechanics of crustal faulting, $J$. Geophys. Res., 97, 5039-5057, 1992.

M. Gurnis, Seismological Laboratory, California Institute of Technology, Pasadena, CA 91125. (e-mail: gurnis@caltech.edu)

S. Zhong, Dept. Earth, Atmospheric, and Planetary Sciences, MIT, Cambridge, MA 02139 (e-mail: szhong@rayleigh.mit.edu)

J. Toth, Shell International, Exploration and Production, Rijswijk, Netherlands (e-mail: J.TOTH@siep.shell.com) 